\title{
The evolution of interindustry technology linkage topics and its analysis framework in 3D printing technology
}

\author{
Zaoli Yang ${ }^{1}$, Nazrul Islam ${ }^{2}$, Yuanyuan $\mathrm{Shi}^{3}$, K. Venkatachalam ${ }^{4}$, Lucheng Huang ${ }^{1}$ \\ ${ }^{1}$ College of Economics and Management, Beijing University of Technology, Beijing, China \\ ${ }^{2}$ Department of Science, Innovation, Technology and Entrepreneurship, University of Exeter \\ Business School, England, UK \\ ${ }^{3}$ Ministry of Transport Planning and Research Institute, Beijing, China \\ ${ }^{4}$ Christ University, Bengaluru, India
}

\begin{abstract}
The mutual influence and complementarity of technologies between different industries are becoming increasingly prominent. Revealing the topic evolution of technology linkages between industries is the foundation for understanding the technological development trend of the industry. Although numerous works have focused on technology topic mining and its evolution characteristics, these works have not accurately represented the interindustry technology linkage, analyze the related topics and even ignored the technological development characteristics hidden in the topic evolution pathway. Since the Lingo algorithm fully considers the time-series characteristics of the topics, and the knowledge evolution theory can reveal three inherent characteristics in the evolution of knowledge topics, namely, "stability, heredity and variability," this paper aims to combine the Lingo algorithm and the knowledge evolution theory to analyze the topic evolution of interindustry technology linkages. Additionally, because 3D printing technology has significant interdisciplinary and cross-industry characteristics, a wide range of application fields, and various interindustry technology linkages, 3D printing technology is used for empirical analysis. The empirical results show that the key topics of interindustry technology linkages in 3D printing include model design, manufacturing methods, manufacturing equipment, manufacturing material and application. In addition, all these topics have the development feature of heredity. However, the topic of manufacturing materials presents significant variability, the topic of manufacturing methods has the strongest stability, and multiple subtopics of the five topics show variability and genetic intersection.
\end{abstract}

Keywords: Topic evolution, Interindustry technology linkage, 3D printing technology, Lingo algorithm, Knowledge evolution 


\section{INTRODUCTION}

Interindustry technology linkage refers to the correlation in which the technologies of different industries influence and complement each other during production [1]. No technology is isolated, and it always has certain relevance with other technologies to form a technological system. The core of interindustry internal connections is technology linkages. Generally, the correlation between technologies is formed by various technology types in different industries due to their complementarities and synergies [1-2]. This correlation makes the change of one technology type cause the chain change of other related technology types, thereby leading to the development, evolution and renewal of the technology system or technology field, that is the chain mode of technology development [3]. Therefore, exploring the topic evolution of interindustry technology linkages will contribute to our understanding of the chain mode of technological development and the evolution law of technological systems or technological fields.

Technological topic evolution is a typical process of knowledge evolution. Actually, knowledge evolution is very similar to biological evolution; in particular, the development of contemporary knowledge coincides with biological hybridization and gene recombination, thereby making it possible to study knowledge evolution by using the theory of biological genetics [4]. According to the definition of genes in biogenetics, knowledge genes are the smallest functional unit of knowledge inheritance and variation; that is, knowledge genes are the basic unit of knowledge inheritance and development [5-6]. The essence of heredity is the inheritance of knowledge, and the essence of variation is the development of knowledge [7]. Therefore, the topic evolution of technology or knowledge is characterized by heredity and variability [8]. A certain key "knowledge element" in related topics may play the role of a "knowledge gene" and determine the evolution and mutation of knowledge in a specific field [6].

Developed in the 1980s, 3D printing technology is a revolutionary "integrated" high technology that relies on high-technology groups, such as computer technology, numerical control technology, laser technology, CAD/CAM technology, and new material technology [9]. Additionally, the basic research of 3D printing technology involves a variety of disciplines, such as physics, chemistry, and materials science, and the application fields of this research are widely distributed [9]. Therefore, 3D printing technology has interdisciplinary and cross-industry characteristics [10]; that is, it shows significant interindustry technology linkage characteristics. 3D printing technology can greatly shorten the product development cycle, improve production efficiency and reduce the cost of human resources required for production [10], so this technology is valued by many countries. However, due to the cross-industry connection characteristics of 3D printing technology, academia and business have still not answered some important questions, such as how to accurately express the interindustry technology linkage characteristics in $3 \mathrm{D}$ printing? What is the development status of the topics on interindustry technology linkage in 3D printing? What are their internal change characteristics? Hence, this article chooses 3D printing technology as a case study to solve these issues. 
Consequently, this study aims to analyze the topic evolution characteristics of interindustry technology linkages by using the Lingo clustering algorithm and the knowledge evolution theory. 3D printing technology is selected as the empirical analysis object, and the patent literature on 3D printing industries in 2013-2017 is used as the data source. Meanwhile, the patents with the interindustry technology linkages in 3D printing are identified by patent citation relationship. Then, the topics on interindustry technology linkages in 3D printing are obtained by using the Lingo algorithm to extract and cluster patent topics. The evolution pathways of the technology topic are explored, and the topic's evolution characteristics - specifically, stability, heredity and variability-are examined based on knowledge evolution theory to uncover the development characteristics and understand the future trends of $3 \mathrm{D}$ printing technology.

The main contributions of this paper include three aspects: first, we construct a topic evolution analysis framework that combines the Lingo algorithm and the knowledge evolution theory. In this framework, the Lingo algorithm is applied to obtain the number distribution of topics in the time dimension and accurately calculate the relevance of topics in adjacent periods. The knowledge evolution theory is introduced to reveal three internal characteristics of the topic evolution-specifically, stability, heredity and variability. Second, we apply the citation relationship between patents and their families to express the interindustry technology linkage. Based on which, the topics on interindustry technology linkage of the patent-based unstructured text in 3D printing technology are extracted and identified. Third, we analyze the topics evolution features of stability, heredity, and variability in 3D printing technology.

The rest of this paper includes the following sections. Section 2 reviews the literature research progress of interindustry technology linkage, knowledge gene, topic evolution analysis, and 3D printing technology. Section 3 constructs the research method, which includes applying the Lingo algorithm to extract and cluster patent topics and applying knowledge evolution theory to examine the evolution characteristics of topics. Section 4 provides the empirical analysis and the results on the topic development features of interindustry technology linkages in 3D printing. Section 5 presents the discussion, conclusions and future work.

\section{LITERATURE REVIEW}

\section{A. Interindustry technology linkage}

Concerning research on interindustry technology linkages, Frankel first analyzed the issue of technology links in the paper "Technology obsolescence and technology evolution in a mature economy" [11]. Then, some scholars studied this issue. Teece examined the characteristics of technology linkage from the perspective of organizational labor division and transaction [12]. Foray and Freeman used a telecommunication network as an example to analyze the role of technology linkages in the evolution of the operation of technical system components [13]. Pavitt et al. pointed out that improving technology linkages encourages more companies to implement technology 
diversification strategies across industries [2]. Then, Carlaw and Lipsey found that with the spread of general technology in the economy, entrepreneurs can use the principle of general technology to create new processes, develop new products, and then generate complex technology networks [14]. Further, Cantwell and Santangelo found that the technical linkage between different production activities is an important factor affecting the merger and acquisition behavior of multinational companies [15]. In addition, Kim and Park applied network theory to analyze Korea's interindustrial technological linkage structure from the early 1980s to the mid-1990s [16]. Liang investigated the impact of the technology linkages between industries on the relationship between foreign direct investment and the productivity of domestic firms [17]. Zhou et al. indicated that cross-industry technological progress, economic scale and energy structure play an important role in the carbon emission efficiency of manufacturing and the electricity/gas/water industries [18]. Ke examined the evolution characteristics of science-technology linkages in biomedical industries [19].

In addition, with the maturity of data mining technology, some scholars have studied the technology linkage network by mining patent information and using a patent co-occurrence matrix [6], thereby forming a research paradigm of industrial technology linkage based on the co-occurrence perspective of patent classification numbers, such as the International Patent Classification (IPC), United States Patent Classification (USPC), and Derwent Classification (DC) numbers. This kind of research focuses mainly on the visualization of the patent co-occurrence matrix, measures of association, measures of technology diversity, etc. [20-24], hoping to determine the internal relationship between research topics and the disciplinary structure of the research field and to reveal the technical structure, technical characteristics and technology development topics of the industry.

\section{B. Knowledge gene}

Relying on Mendel's inheritance law and Weismann's germplasm theory, Morgan proposed the gene theory. Genes are the genetic unit of biological evolution, have stability and transmissibility and determine the genetic status of organisms [25]. In accordance with gene theory, Dawkins proposed the concept of a thought gene and pointed out that the thought gene transplants, expands and reproduces with changes in time and space, similar to biology [26]. On this basis, some scholars presented the concept of knowledge genes and defined knowledge genes as the smallest functional unit of knowledge inheritance and variation $[5,27]$. In terms of function, knowledge genes are an indecomposable independent unit, but in terms of structure, knowledge genes are decomposable [27]. Knowledge genes have stability, dominance, heredity, variability and the ability to control the direction of knowledge; the most important and fundamental of these characteristics are heredity and variability [28].

Due to the intangibility of knowledge genes and the indirectness of their effect, research on knowledge genes is generally conducted indirectly; that is, the carriers of knowledge genes, such as academic papers, scientific and technological products, and technological achievements, are investigated [27-28]. Among these carriers, patents, as the core content of technological innovation 
achievements, contain relevant knowledge to solve a specific technological problem [29]. A new patent is usually associated with some early patents; that is, the existing patents often inherit and develop all or part of the knowledge in the early patents [30-31]. From the perspective of biogenetics, early patents can transfer knowledge to later patents through citation, which reflects the relationship of heredity, inheritance and development of patent knowledge. Therefore, patents are a unique information tool for discovering the origin and evolution of technological knowledge.

Huang et al. analyzed longitudinal research and development (R\&D) in nanoscience and engineering by using information from the United States Patent and Trademark Office (USPTO) [32]. Chen and Hicks used tissue engineering as an example to investigate the knowledge transfer mechanism between academic and engineering circles by analyzing the citation relationship between papers and patents [33]. Daim et al. combined the patent co-citation method with complex network theory to forecast technological orientation [34]. Similarly, Li et al. integrated patent co-citation analysis and text mining algorithms to identify the development trends of nanogenerator technology [35]. The above similar ideas are widely applied to various fields of joint development on artificial intelligence technologies [36] and technological collaborations on carbon capture and storage [37]. These studies explored knowledge diffusion, technology transfer and technology evolution by examining patents and patent citations.

\section{Topic evolution analysis}

Exploring topic evolution is essential to analyze and calculate topics with time characteristics at the semantic level. Topic evolution analysis has two tasks: to reveal the evolution trend of the topic and to reveal the evolution content of the topic [38]. By fusing the concepts of "natural orbit" and "scientific paradigm", Dosi proposed the definition of technological orbit, that is, the orbit of technological progress defined by the technological paradigm [39]. Due to the hierarchical and progressive characteristics of the topic features contained in the technology topic, the evolution of the technology topic is an evolutionary activity along the development direction of the technology orbit under the constraints of the technology paradigm [40]. Many scholars have proposed many topic evolution models using continuous time slices and variable topic analysis, such as the earlier topic over time (TOT) model [41], dynamic topic model (DTM) [42], dynamic mixture model (DMM) [43], and others [44-48]. These topic models and their extensions have been used in a wide variety of applications, such as assessments of enterprise ecosystems [49], cross-domain recommendations [50], forecasting emerging technologies [51], understanding user preferences [52], and patent information mining [53].

Patent literature, as the carrier of knowledge dissemination, is an important information resource of science and technology, business and law. Patent information includes not only the patentee, patent classification number, patent No. and other structured information provided by the patent database, but also the technical content, abstract, specification and other unstructured information recorded by the patent text. Because of this wealth of information, patent topic mining based on the structured 
information in patent databases has been widely considered by authors and focuses mainly [33-35]. Of which, the keyword co-occurrence is the most common patent topic analysis method $[22,54]$. As the patent literature does not contain keyword fields, scholars usually use patent classification codes, such as the IPC and Derwent manual code, to replace patent keyword fields for technical topic mining [5556]. However, they have the following limitations: first, patent classification number is a classification principle based on functionality and supplemented by application, which is difficult to correspond with specific industrial technology fields; secondly, there are a large number of patents of the same function under the same sub-classification number, so the classification is too broad to reflect the cutting-edge fields and key technologies; finally, these classification codes are usually updated every few years, which is difficult to reflect the latest technological changes in time. For those issues, some researchers began to apply text mining technology to extract "terms" from the patent text content as topic words $[35,57-58]$.

Text mining not merely provides a new idea for patent topic analysis, but also establishes an important pathway for effectively mining patent information. In addition, Derwent innovation index (DII) is one of the most famous patent databases in the world. It has the characteristics of large amount of patent data, high update frequency and high added value of information, etc. Due to the authority of its data, the DII is also used as the retrieval database of patent examination by many patent offices. In addition, the DII shows the citation relationship of patents comprehensively, so it has been adopted by many scholars for technical analysis from multiple perspectives [34-35, 57]. Therefore, our study is also based on the DII to mine the citation relationship of related patents, so as to accurately characterize the interindustry technology linkage.

\section{D. $3 D$ printing technology}

$3 \mathrm{D}$ printing is a new technology in the field of manufacturing, which has the characteristics of interdisciplinary and cross industry [9]. It possesses some significant advantages over traditional manufacturing, including large-scale customization, reduced technology R\&D costs, more agile supply chains, and optimized organizational structures and business models [10]. 3D printing has become an effective method for the manufacture of modern models, molds and parts and it is widely used in aerospace, automotive manufacturing, biomedicine, engineering construction, teaching research and other aspects [59]. There are abundant studies on 3D printing technology, which can be summarized into three aspects from the pure technical level: additive manufacturing technology, material and application [59]. In addition, many scholars have analyzed the impact of 3D printing technology on society and economy. For example, Chan et al. examined the impact of 3D printing on supply chain performance from the perspective of supply chain integration and intellectual property rights [60]. Shahrubudin et al. explored the evolution of 3D printing technology and its numerous social, economic, geopolitical, security and environmental consequences [59]. Khosravani and Reinicke analyzed the environmental impacts of 3D printing technology from the perspectives of the energy, waste material 
and air pollution [61].

Besides, with the rapid development of 3D printing technology, many authors try to reveal the evolution characteristics and pathways of 3D printing technology. For instance, Park et al. constructed a method framework consisting of the time series regression, graph theory-based association analysis, and principal component analysis to obtain the understanding of the technological evolution of 3D printing [62]. Trappey et al. developed the ontology-based patent concept analysis to explore the biomedical 3D printing technology trends through extracting the frequently appearing key terms in patents [63]. Huang et al. applied the co-classification method to reveal the evolution process of 3D printing technology by extracting implicit or unknown patterns and topics [64]. Zhou et al. presented a semi-supervised topic clustering model of labeled Dirichlet multi mixture model to identify emerging technologies in 3D printing industry [65]. Similarly, Wang et al. applied the principal components analysis to identify the emergent topics of technological convergence in 3D printing field [66]. After that, Chen et al. mined the patent abstract to track the evolution trend and identified the potential R\&D hotspots of 3D printing technology [53]. Miao et al. drew the evolution pathway of 3D printing technology in different time periods, and the results showed that the traditional technologies of 3D printing follow a declining trend, while the practical application of it is a promising direction [67]. Meanwhile, Wang et al. mapped the trajectory of technological development and investigated the contribution of various knowledge sources of $3 \mathrm{D}$ printing technology based on the patent citation data [68]. It can be seen that the above studies mainly carried out macro statistical analysis for structured data such as the number of patents, and seldom involved the topic mining based on unstructured text of patent. As a result, the extracted information cannot fully explain the 3D printing technology. Further, 3D printing has significant cross-industry characteristics, but the existing works did not focus on the interindustry technology linkage in 3D printing. Consequently, the results by these studies are difficult to reflect the level of cross-industry integration and application of 3D printing technology, and ultimately affect our understanding of the development trend of 3D printing technology.

In summary, previous studies have made many contributions to interindustry technology linkages, knowledge genes, topic evolution analysis, and 3D printing technology. However, the existing works on interindustry technology linkage mainly elaborated its influence effect from the macro perspective, and indirectly represented the interindustry technology linkage using the patent co-occurrence matrix instead of patent cited relationship. Meanwhile, studies on the evolution of 3D printing technology topics are still based on structural data, such as the IPC, without extending to the level of patent text, and ignored the topics analysis of interindustry technology linkage for reflecting the cross-industry characteristics of 3D printing technology. All of the above possibly prevent us from understanding the essence of technology and discovering new results of 3D printing technology. Further, concerning research on knowledge genes, previous works have analyzed technology evolution only from the perspective of patent citation relationships and simple timing statistics to indirectly reflect the characteristics of knowledge genes. Such research does not directly apply the stability, heredity and 
variability of knowledge genes to investigate the development trend of technology topics, thereby inevitably affecting our judgment of technological topic evolution law. Besides, in terms of topic evolution, the existing research fails to consider the time attributes of the topic, calculate the relevance of the topic in adjacent periods, and reveal the evolution path of the topic; consequently, we cannot obtain the inherent characteristics of knowledge topic evolution.

Therefore, this paper attempts to address the following gaps in current studies:

How can interindustry technology linkage be accurately represented from the patent perspective?

How can the topics of interindustry technology linkages in 3D printing technology be identified based on unstructured patent text?

How can the relevance of topics be calculated in adjacent periods to reveal the evolution pathways of 3D printing topics?

How can the change characteristics of stability, heredity, and variability in the $3 \mathrm{D}$ printing topic evolution be analyzed?

To address the above issues, this paper uses the Lingo algorithm and the knowledge gene theory to analyze the evolution of interindustry technology linkage topics in the case of 3D printing technology. First, the inner connection between knowledge evolution and biological evolution is established from the theoretical perspective. Second, the patents of interindustry technology linkage on 3D printing in the DII are captured by identifying the cited relationship, and the Lingo algorithm is used to extract and cluster patent topics and obtain the number of clustering topics under the time dimension. The clustering results are combined with the topic keyword analysis after classification to generate the time trend of topic evolution by using Carrot software. Additionally, the similarity formula is used to calculate the correlation of topics in adjacent periods and to analyze the evolution pathways of the topics. Third, three characteristics of knowledge genes in knowledge evolution, namely, stability, heredity and variability, are used to analyze the characteristics of topic evolution. Finally, the development trend features of the topics of interindustry technology linkage on 3D printing are investigated based on the above three characteristics.

\section{ReSEARCH Methodology}

The internal relationship between knowledge evolution and biological evolution is theoretically analyzed to reveal that knowledge genes have the same characteristics of stability, heredity and variability found in biological evolution. Based on that, first, we need to collect relevant data and process it. Then, the Lingo algorithm [69] is applied to mine the knowledge topics with time-series characteristics, as the topic correlation between adjacent periods is calculated and the evolution path of the topic is identified [5]. Finally, the knowledge gene is used to analyze the stability, heredity and variability in the evolution of topics. The outline of the research methodology is demonstrated in Fig. 1. Before the method in Fig. 1 is implemented, the internal relationship between knowledge evolution 
and biological evolution is theoretically analyzed, which also provides a theoretical basis for the application of the method in Fig. 1. In addition, the step 1 in Fig. 1 will be shown in detail in the subsequent empirical analysis section of this paper.

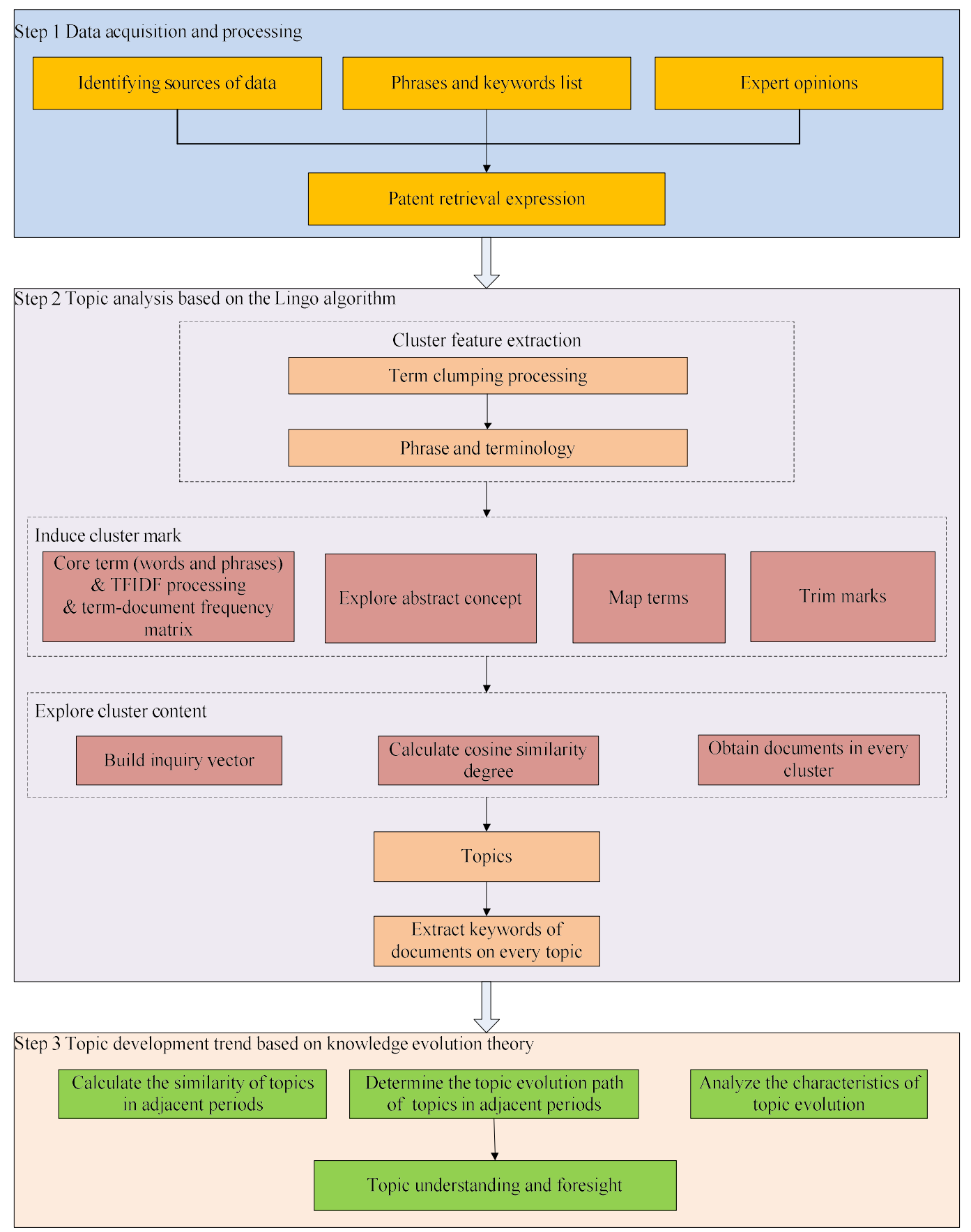

Fig. 1. Outline of the research methodology

\section{A. The inner connection between knowledge evolution and biological evolution}

According to the principle of biological evolution [70], knowledge and biological genes have similar characteristics. Therefore, based on Darwinism [70], knowledge creation is characterized by 
uncertainty, arbitrariness, and freedom from human subjective consciousness. Additionally, knowledge has a clearer direction and predictable results in the process of change [71]. The selection, retention and variation of knowledge genes are the fundamental reasons for knowledge creation. In addition, the direction of knowledge change is affected by the environment, so the driving force of knowledge change comes from the adaptation of the knowledge subject to the environment. In contrast, new knowledge can also change the environment. Similarly, in technological innovation evolution, the topic extracted from knowledge is an important part of knowledge, and its changes also have the characteristics of knowledge development [8], that is, knowledge topic evolution.

The reason why knowledge can evolve is inseparable from the biological attributes of knowledge itself. Fig. 2 shows that knowledge evolution is highly similar to biological evolution, especially in recent years. The burst of knowledge coincides with the biological evolution of biological hybridization and genetic recombination; this coincidence establishes a direct correlation between biological genetics and knowledge evolution [7]. Therefore, according to McKelvey's theory [72], knowledge evolution has the following four characteristics:

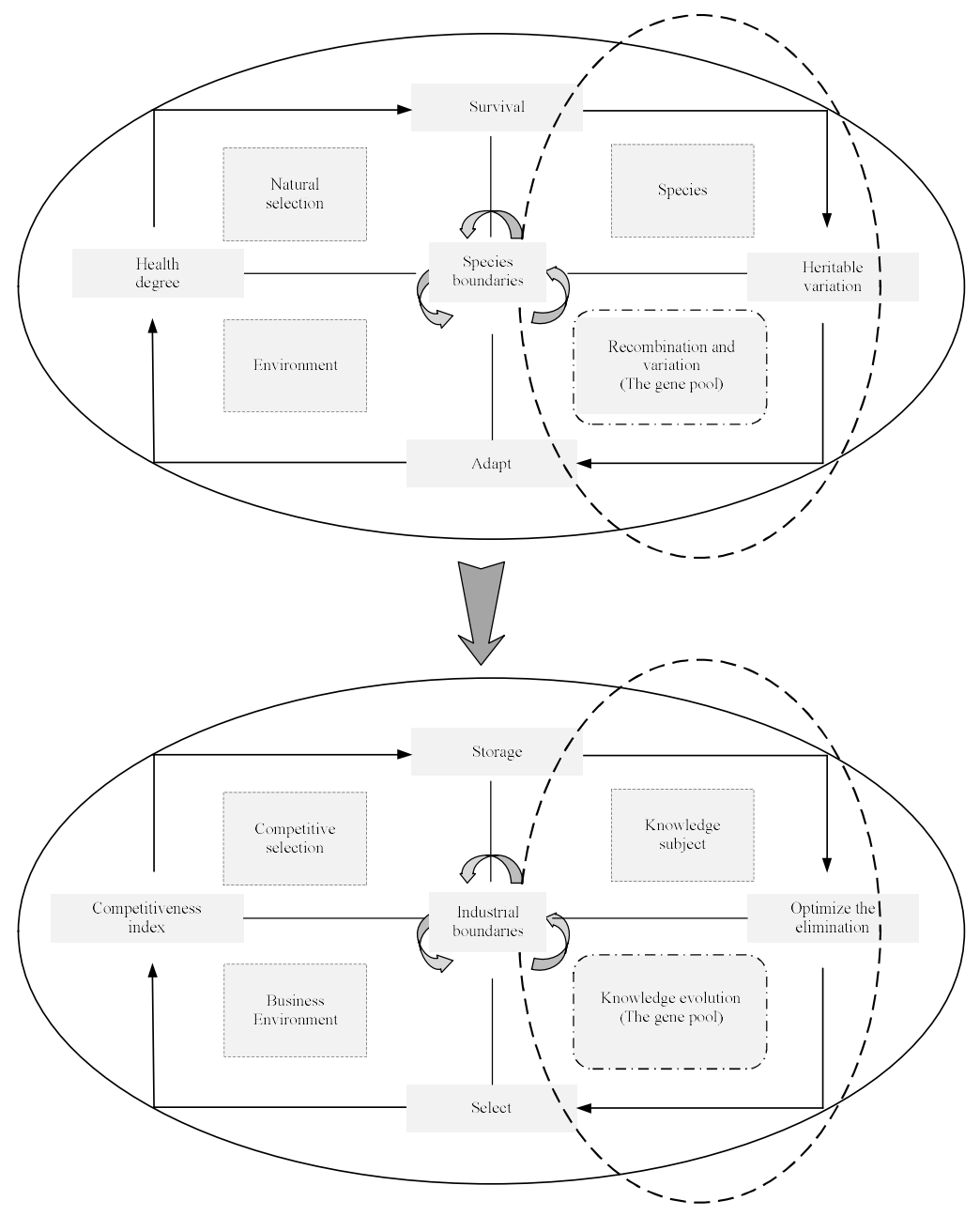

Fig. 2. From biological evolution to knowledge evolution 
1) Knowledge variation: New knowledge often comes from the transformation of old and existing knowledge; according to the theory of evolution, this process can be called knowledge variation. When dealing with changes in the objective environment, the technological knowledge of interindustry linkages is inherently different and inconsistent [73]. Therefore, knowledge variation means that the creation of knowledge changes the original specific knowledge from content to structure.

2) Knowledge selection: The objective environment will purposely select some knowledge to eliminate and select some technologies for retention or innovation.

3) Retention and storage of knowledge: New adaptive knowledge can be retained and stored and can flow between industries.

4) Knowledge competition: The resources in the environment where knowledge is located are limited; consequently, there will competition between domains of knowledge.

According to biological evolution theory, the characteristics of knowledge variation in knowledge evolution correspond to species variation, the retention part in the selection of knowledge, and the survival part in the competition of knowledge; the retention and storage of knowledge are regarded as the stability of the species; and the innovation in the knowledge selection is similar to the heredity of species. That is, knowledge evolution has three characteristics: knowledge stability, heredity and variability. In accordance with these three characteristics, we use 3D printing technology as the empirical object and apply the Lingo algorithm to obtain knowledge topics and knowledge gene theory to examine the features of stability, heredity and variability in the topic evolution to uncover the intrinsic law of evolution with respect to $3 \mathrm{D}$ printing technology. The specific calculation method is as follows:

\section{B. Lingo algorithm}

The Lingo algorithm is a typical algorithm describing the priority [69]. Compared with the traditional clustering algorithm, the unique feature of the Lingo algorithm is that it first identifies the meaningful clusters while distributing only the valid search results into these tags to construct appropriate clustering. The calculation steps of this method include the following three main stages [69]:

\section{1) Extraction of clustering feature}

First, the documents are obtained according to the user's search requirements, and conjugate processing and stop word filtering are carried out for these documents to be processed. Then, feature words are extracted. To achieve a better clustering effect, feature selection (the selection of phrases and terms) should conform to the following rules:

a. The occurrence frequency of feature words in the document should meet a certain threshold;

b. One should not go beyond the boundaries of a sentence;

c. The feature words should be a complete phrase (a complete phrase cannot be preceded or followed by a new word); and 
d. The feature words should not be in front of or behind the stop words.

In this paper, the TF-IDF method is used to extract the required keywords. These keywords may be single words or phrases, and tags will be selected from these selected words and phrases.

2) Marker of inductive clustering

Inductive clustering is needed for the selected words or phrase tags. There are four steps for marking in inductive clustering: construction of a terminology-document frequency matrix, abstract concept discovery, phrase mapping, and marker trimming. The details are as follows:

Construction of terminology - document frequency matrix: construct the terminology - document frequency matrix A by using TF-IDF; if some terms appear in the title of the article, they shall be normalized by constant factors.

Abstract concept discovery: First, singular value decomposition (SVD) of matrix A is carried out to obtain its orthogonal basis, namely:

$$
A=U^{*} S^{*} V^{T}
$$

The base vector of $U$ represents the abstract concept that appears in the paper. In the subsequent process of the algorithm, only the first $k$ vectors of $U$ are taken.

Then, the value of $k$ is determined by the Frobenius norm of $A$ and the $k$-order approximate matrix of $A$. Additionally, the threshold $q$ in the model is used to determine how much information of original matrix $A$ is contained in the approximate matrix $A_{k} . k$ can be defined as the minimum value satisfying $\left\|A_{k}\right\| /\|A\|_{F} \geq q$, and $\left\|A_{k}\right\|_{F}$ is the Frobenius norm of $F$. The larger the value of $q$ is, the more features that can be used for clustering, and $q$ is a parameter that can be set by users.

Phrase mapping: The abstract features need to be mapped with specific phrases or attributes. The matrix $U$ has been constructed in the stage of abstract concept discovery, and the physical meaning of $U$ is as follows: the row vector represents terms, and the column vector represents abstract features; therefore, the classical cosine distance algorithm can be used to calculate the distance between phrase or term and abstract concept. The matrix $P$ of $t \times(p+t)$ is constructed for this purpose, where $t$ represents terms and $p$ represents phrases. If phrases and terms are regarded as virtual documents, a matrix $P$ similar to $A$ can be constructed, where the $i^{\text {th }}$ column of $U$ is multiplied by the matrix $P$ to obtain:

$$
m_{i}=U_{i}^{T} * P
$$

The phrase corresponding to the largest element in $m_{i}$ will be selected as the real concept corresponding to the $i^{\text {th }}$ abstract concept. In addition, the elements in $m_{i}$ can also be used as tag scores of clustering features. 
Marker trimming: Some phrases in the candidate clustering feature set are in the phrase mapping stage, and these phrases can be used as the clustering category, but these features are redundant, so we need to remove these repeated features in the marker trimming stage. For this purpose, the terminologydocument matrix $Z$ shall first be constructed. The document here is the phrase in the feature set. The $i^{\text {th }}$ row of $Z^{T} Z$ represents the cosine similarity between the $i^{\text {th }}$ feature and other features. Some elements larger than a certain threshold value are selected from each row (excluding diagonal elements), and the feature corresponding to the largest element value selected from these elements can be regarded as the final candidate feature.

\section{3) Mining of clustering content}

According to the inductive clustering marker, documents can be divided into several categories, and each category has a certain corresponding topic. Then, these topics are applied to construct query vectors and calculate the cosine similarity between these query vectors and the original terminologydocument matrix to obtain the documents that should be included in each category. The document matrix $Q$ is constructed according to the documents in each category. Each row represents the term, and each column represents the feature (phrase); therefore, we can obtain:

$$
C=Q^{T} A
$$

$A$ is the original terminology-document matrix. From the elements in each row of $C$, documents larger than a certain threshold are selected as a category. If some documents belong to no category, these documents are classified into one category.

According to the above three steps, topic $T$ at time $t$ and its topic term vector are finally obtained as follows:

$$
T^{t}=\left\{T_{1}^{t}, T_{2}^{t}, \cdots, T_{i}^{t}, \cdots, T_{s}^{t}\right\}
$$

\section{Identification of topic evolution pathways}

1) Calculation of the relevance of topics in adjacent periods

Among the identified topics in adjacent periods, only related topics can form the evolutionary relationship between topics. To identify related topics, the correlation between two topics is determined by calculating the similarity between topics by using the formula below [74]:

$$
\operatorname{Sim}\left(T_{i}^{t}, T_{j}^{t \pm 1}\right)=\frac{\left|T_{i}^{t}\right| \times\left|T_{j}^{t \pm 1}\right|}{\sqrt{\left(T_{i}^{t}\right)^{2}} \times \sqrt{\left(T_{j}^{t \pm 1}\right)^{2}}}
$$

where $T_{i}^{t}$ represents the topic at time $t$, and $T_{j}^{t \pm 1}$ represents the topic at time $t \pm 1$. 
2) Evolution pathways of topics in adjacent periods

First, two kinds of correlation relations between topics in adjacent periods are defined as follows according to the sequential order of related topics:

Forward topic: for topic $T_{i}^{t}$ at time $t$, find topic $T_{i}^{t-1}$ at the previous time $t-1$, which is most similar to $T_{i}^{t}$. If $\operatorname{Sim}\left(T_{i}^{t}, T_{j}^{t-1}\right) \leq \varepsilon$ is satisfied, $T_{i}^{t-1}$ is the forward topic of $T_{i}^{t}$.

Backward topic: For topic $T_{i}^{t}$ at time t, find topic $T_{i}^{t+1}$ at the latter time $t+1$, which is most similar to $T_{i}^{t}$. If $\operatorname{Sim}\left(T_{i}^{t}, T_{j}^{t+1}\right) \leq \varepsilon$ is satisfied, $T_{i}^{t-1}$ is the forward topic of $T_{i}^{t}$.

Then, the evolution of the topic can be deduced according to the association relationship between the current topic and its forward topic and backward topic. In this paper, their relationship is divided into five categories: new birth, extinction, temporary emergence, inheritance and resurrection, as shown in Fig. 3.

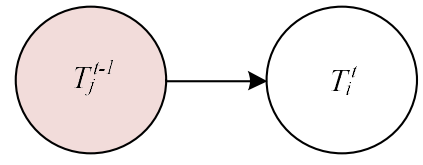

a

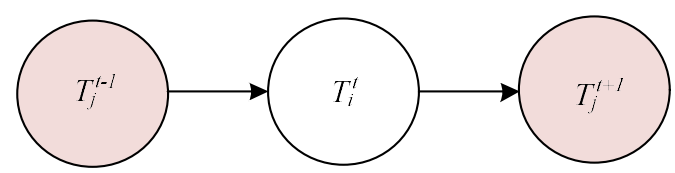

c

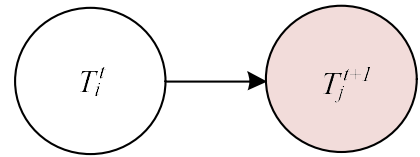

b

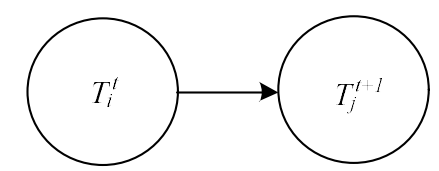

d

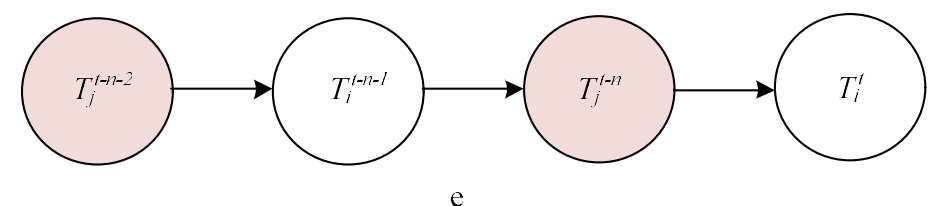

Fig. 3. Topic evolution pathways

New birth: If topic $T_{i}^{t}$ has no forward topic and there is no topic with backward topic $T_{i}^{t}$ at time window $t-1, T_{i}^{t}$ is considered to be a new topic at $t$, as shown in Fig. 3(a);

Extinction: If topic $T_{i}^{t}$ has no backward topic and there is no topic with forward topic $T_{i}^{t}$ at time window $t+1, T_{i}^{t}$ is considered to be an extinction topic at $t$, as shown in Fig. 3(b);

Temporary emergence topic: If the topic $T_{i}^{t}$ has no forward topic and there is no topic with topic $T_{i}^{t}$ at time window $t+1$, then $T_{i}^{t}$ is considered to be a temporary emergence topic, which will not achieve further development after a temporary emergence and then go to extinction, as shown in Fig. 3(c); 
Inheritance topic: Assuming that the backward topic of the topic $T_{i}^{t}$ is $T_{j}^{t+1}$ and the forward topic of $T_{j}^{t+1}$ is $T_{i}^{t}$, then it is believed that $T_{j}^{t+1}$ and $T_{i}^{t}$ are the expressions of the same topic in different periods, namely, $T_{j}^{t+1}$ inherits from $T_{i}^{t}$, as shown in Fig. 3(d).

Resurrection topic: If topic $T_{i}^{t}$ has forward topic $T_{i}^{t-n-1}$ before $\mathrm{n}$ periods but has no inheritance topic in the middle $n$ periods, then $T_{i}^{t}$ is believed to be the resurrection topic in the middle of $n$ periods; this topic will disappear in the short term after temporary emergence and then appear again, as shown in Fig. 3(e).

\section{Topic evolution characteristics based on knowledge genes}

According to the five types of topic relationships, namely, new birth, extinction, temporary emergence, inheritance and resurrection, the knowledge gene theory in knowledge evolution is used to analyze the stability, heredity and variability of topics.

Stability can be identified according to the continuity of newly born topics in a certain period. In some special cases, although there is a short-term extinction, the topic will be resurrected soon, and the topic that appears has the same meaning as the topic that was extinct before; that is, such topics are very similar, so the stability can also be judged.

Regarding heredity, if a topic is very similar to its forward topic, that is, if the topic is inherited from the forward topic, then it can be determined that the topic is inherited from the forward topic.

Regarding variability, if the temporary emergence, inheritance and resurrection topics are slightly similar to the forward topics at one or more forward times or if these topics and their backward topics appearing at one or more times are slightly similar, then these topics have variability.

Therefore, the stability, heredity and variability of the topic evolution can be comprehensively analyzed to determine the evolution law of the topic and determine the development trend of the topic.

\section{EMPIRICAL RESULTS}

\section{A. Data sources}

3D printing is based on digital model files that use adhesive materials, such as powdered metal or plastic, to construct objects by printing layer by layer. As a comprehensive application technology, 3D printing involves a wide range of technologies with a high technological content and involves many industrial fields, so this technology has the features of a wide range of applications and interindustry technology linkages. The emergence and development of this new technology will subvert the industrial development mode. Therefore, the patent data can be analyzed to obtain the technological association topics among related industries and draw the development path of associated topics; such an analysis can help the government, scientific research institutions and enterprises grasp the law of technological development and the future industrial development focus. In this paper, the DII is used as the data source, and a series of phrases and keywords for data compilation are collected from relevant literature, 
media reports and network information. Then, relevant keywords are screened or supplemented in combination with expert opinions. Finally, the retrieval expression is obtained as follows:

$\mathrm{TI}=(("$ three dimension* print*") or ("3D print*") or ("rapid* prototype*") or ("additive* manufact*") or ("digital* manufact*") or ("intelligent* manufact*") or ("additive* prototype*") or ("rapid* prototype* manufact*"))

Thus, the number of patents related to the 3D printing industry with a time span from 2013 to 2017 is obtained, as shown in Fig. 4.

During this period, the number of patents in 3D printing technology showed a rapid growth trend. Especially, the growth rate in 2016 had reached $300 \%$ compared with that in 2015 . This is in line with the situation that the $3 \mathrm{D}$ printing technology was popular in the market at that time. Although the absolute number of patents related to 3D printing technology is very considerable, the number of interindustry technology linkage patents among them is unclear. The 3D printing technology has significant interdisciplinary and cross industry characteristics, so the patent status of interindustry technology linkages can reflect the real activity and performance level of $3 \mathrm{D}$ printing technology in application. For this reason, we need to further examine how much of the number of patents in Fig.4 that reflect interindustry technology linkages, so as to explore the application and integration level of $3 \mathrm{D}$ printing technology in various fields.

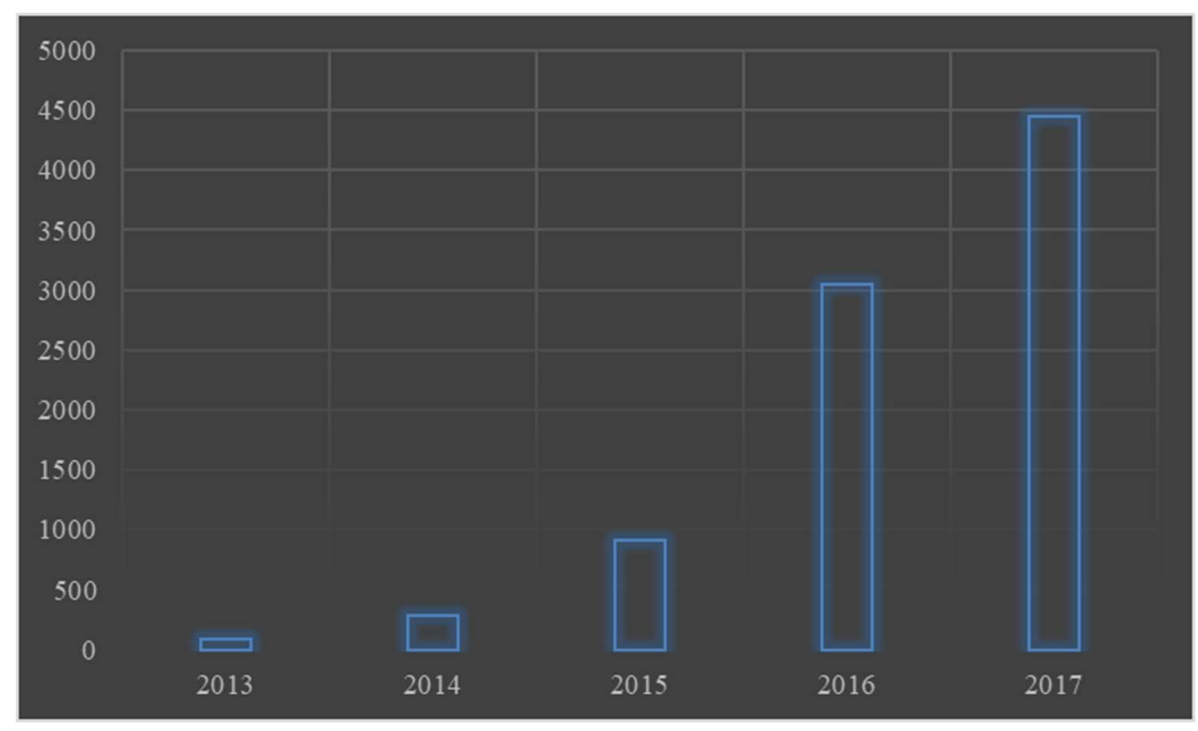

Fig. 4. Number of patents on 3D printing technologies

\section{B. Identification of the patents for representing the interindustry technology linkages}

The patent literature contains citation information in the DII, which indicates that there is a technical connection between patents and their families. Specifically, if a patent and its family are cited by other patents, then the technology in the cited patent is output to the citing patent. Conversely, if a patent and 
its family cite other patents, then the patent and its family import technology from other patents, so the connection between the two technologies is created. Therefore, the citation relationship between patents and their families can be regarded as the interconnection between technologies. Based on the above, we screen out patent documents with cross-industry citation relationships by using a self-compiled program. Using patent citation data, JAVA software is taken to extract the inter-patent citation matrix and realize automatic classification of the patent industry. The process is shown in Fig. 5, which includes 13 steps for clearly describing from downloading the patent literature to obtaining the patents on interindustry technology linkages. Actually, the 13 steps can be summarized into five aspects, namely, inputting the patent documents, extracting the specific information from the patent documents, listing patents in rows and columns according to their citation and being cited, identifying the patents with or without citations, constructing the patent citation relation matrix.

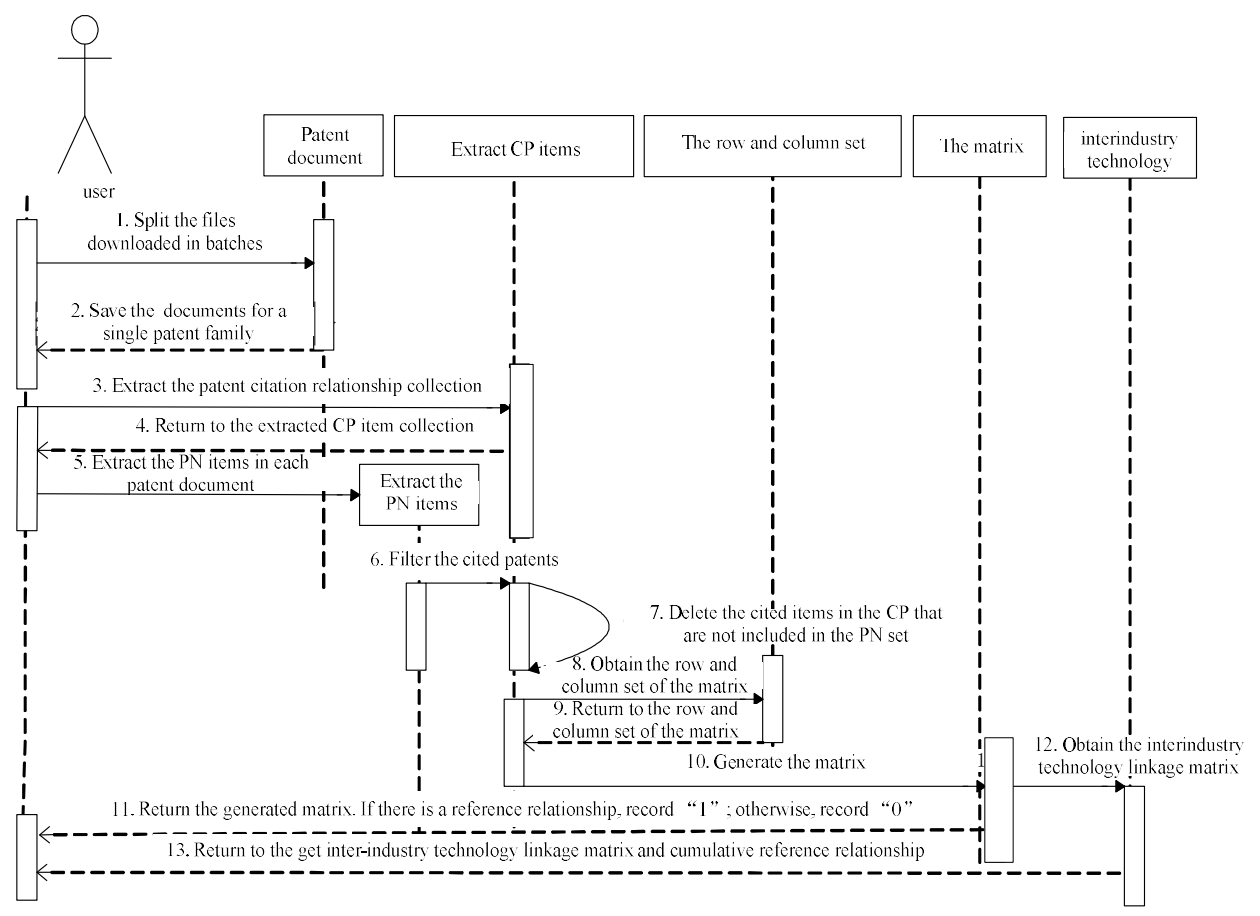

Fig. 5. Generating the citation matrix between patents

According to the steps in Fig. 5, we finally obtain the citation matrix between interindustry technology linkage patents in 3D printing, as shown in Table 1. Since the dimensions of the matrix are very large, we list only some of the patent citation relationships in the matrix as examples for illustration. In Table 1, the row is the citation patent, and the column is the cited patents, " 0 " means that there is no citation relationship between patents, and 1 means that there is a citation relationship between patents. For example, as shown in Table 1, the relationship between the patent US5204055-A and the patent US8185244-B2 is marked as 1, indicating that there is a citation relationship between the two patents and their families. According to the patent literatures, they both focus on manufacturing molds 
in 3D printing, but the US5204055-A is in the field of materials, while US8185242-B2 belongs to the field of dental implants, which means the interindustry technology linkage in the aspect of manufacturing molds.

TABLE 1. CitATION MATRIX BETWEEN INTERINDUSTRY TECHNOLOGY LINKAGE PATENTS IN 3D PRINTING

\begin{tabular}{|c|c|c|c|c|c|c|}
\hline & $\ldots \ldots$ & US5204055-A & US5340656-A & EP431924-B1 & US5807437-A & $\ldots \ldots$ \\
\hline$\ldots \ldots$ & $\cdots \cdots$ & $\ldots \ldots$ & $\ldots \ldots$ & $\cdots \cdots$ & $\ldots \ldots$ & \\
\hline $\begin{array}{c}\text { WO2008103450 } \\
-\mathrm{A} 2\end{array}$ & ...... & 0 & 0 & 1 & 0 & \\
\hline US8185224-B2 & $\ldots \ldots$ & 1 & 0 & 0 & 0 & ...... \\
\hline US7589868-B2 & $\ldots \ldots$ & 0 & 0 & 0 & 0 & $\ldots$ \\
\hline $\begin{array}{c}\text { WO2004044816 } \\
-A 1\end{array}$ & ...... & 0 & 0 & 0 & 0 & \\
\hline$\ldots \ldots$ & $\ldots \ldots$ & $\ldots \ldots$ & $\ldots \ldots$ & $\ldots \ldots$ & $\ldots \ldots$ & $\ldots \ldots$ \\
\hline
\end{tabular}

Finally, we obtain the number of interindustry technology linkage patents in $3 \mathrm{D}$ printing over different years as shown in Fig. 6.

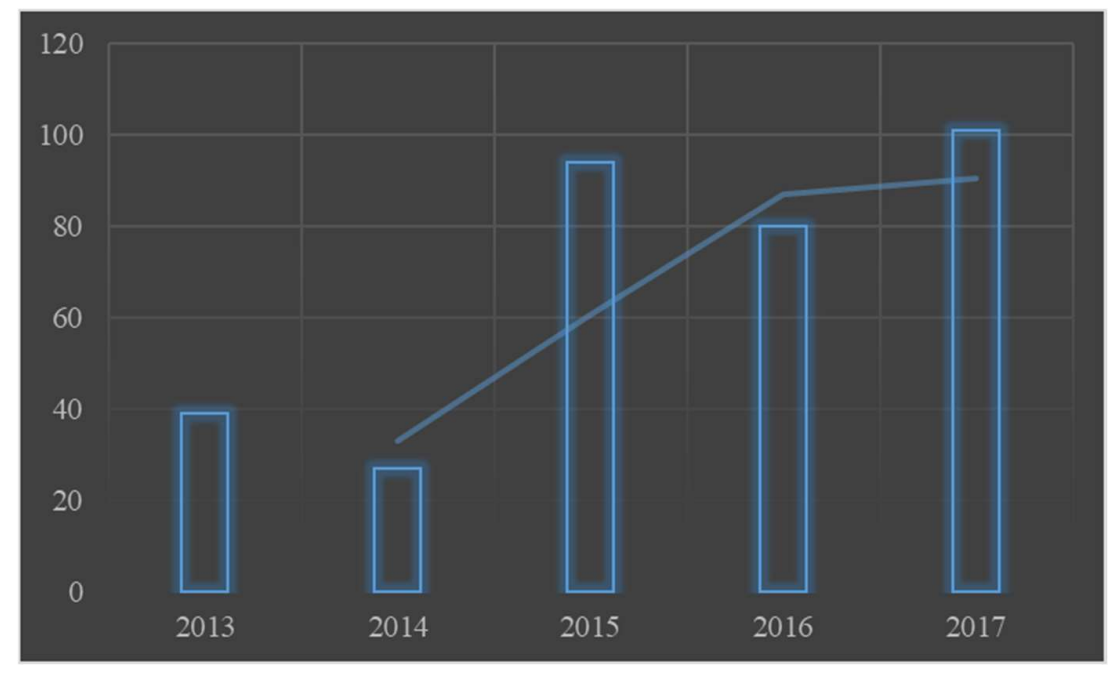

Fig. 6. Number of interindustry technology linkage patents in 3D printing

As shown in the Fig. 6, the number of interindustry technology linkage patents in 3D printing is growing on the whole, which shows that the interdisciplinary and cross-industry characteristics of 3D printing technology are more and more significant, that is, 3D printing technology is accelerating the integration of various industries in pure technology $R \& D$, materials and applications. On an annual basis, the number of interindustry technology linkage patents in 3D printing in 2014 was the smallest, and it increased more than 2 times in 2015. Although it declined in 2016, it recovered in 2017. This indicates that the growth of the number of interindustry technology linkage patents in $3 \mathrm{D}$ printing is 
unstable. The main reason is that there are still many challenges in printing speed, material availability, accuracy and manipulation, as well as disputes in legal liability. Generally, this growth trend is consistent with the cessation of large-scale cross industry diffusion of 3D printing technology and its uncertainty in the future. This has further inspired us to explore the evolution trend of 3D printing technology from the perspective of interindustry technology linkage, providing a better understanding of the development pathways and opportunities of 3D printing technology.

\section{Topic extraction and cluster analysis based on the Lingo algorithm}

Then, the time division of the selected patent literature is carried out according to the patent application time. Additionally, topic extraction and clustering of effective literature is performed by using the Lingo algorithm. In this step, the algorithm nested in Carrot 2 software can be used to manage the stop list and adjust the maximum cluster size, the number of clusters, the weight of each word, the TF/IDF ratio and other parameters to optimize the clustering step. Finally, the number of topic clusters in different years and the literature under each topic are obtained. The more popular or mature topics are selected as the analysis objects, and the number of topics in each year is shown in the Table 2 . According to the Table 2, the number of interindustry technology linkage topics in $3 \mathrm{D}$ printing has a certain fluctuation during 2013-2017, which is similar to the corresponding fluctuation in the distribution of the number of patents, but there is no linear relationship between them. As shown in Fig.6, the number of interindustry technology linkage patents in 3D printing in 2016 is lower than that in 2015 and 2017, while the number of interindustry technology linkage topics in 2016 shown in Table 2 is the largest during this period. It can be seen that interindustry technology linkage topics in 3D printing may have the characteristics of rebirth, extinction, inheritance and variation in different years.

TABLE 2. NUMBER OF TOPICS PER YEAR

\begin{tabular}{llllll}
\hline Year & 2013 & 2014 & 2015 & 2016 & 2017 \\
\hline Number & 12 & 18 & 21 & 25 & 20 \\
\hline
\end{tabular}

Subsequently, to better illustrate the basic variations of the topics in Table 2, a map of the topic evolution with the characteristics of interindustry technology linkages is drawn, as shown in Fig. 7. According to the actual meaning of each topic word, all topics are classified into five aspects, namely, model design, manufacturing methods, manufacturing equipment, manufacturing material and application. According to the Fig.7, the distribution characteristics of the topics in the five aspects are completely different in different years. Specifically, in the model design, there are obvious differences between the topics of each year. For example, in 2013, the topic was models; in 2014, it changed to computer model; and in 2016, it changed to new physical models. In the manufacturing methods, almost all of its six topics appeared every year, that is, these six topics remain unchanged from 2013 to 2017. In the aspect of manufacturing equipment, most of the topics appeared in one issue and then 
disappeared. In the manufacturing materials, each topic presented complex and differentiated evolution characteristics. For example, the powder topic remained a stable and unchanged state from 2013 to 2017, while the multiple materials and hydrogen die out only once. In the application, it has similar complex change characteristics with the topic of manufacturing material. Therefore, we need to further uncover the internal evolution characteristics of various topics in different aspects. 


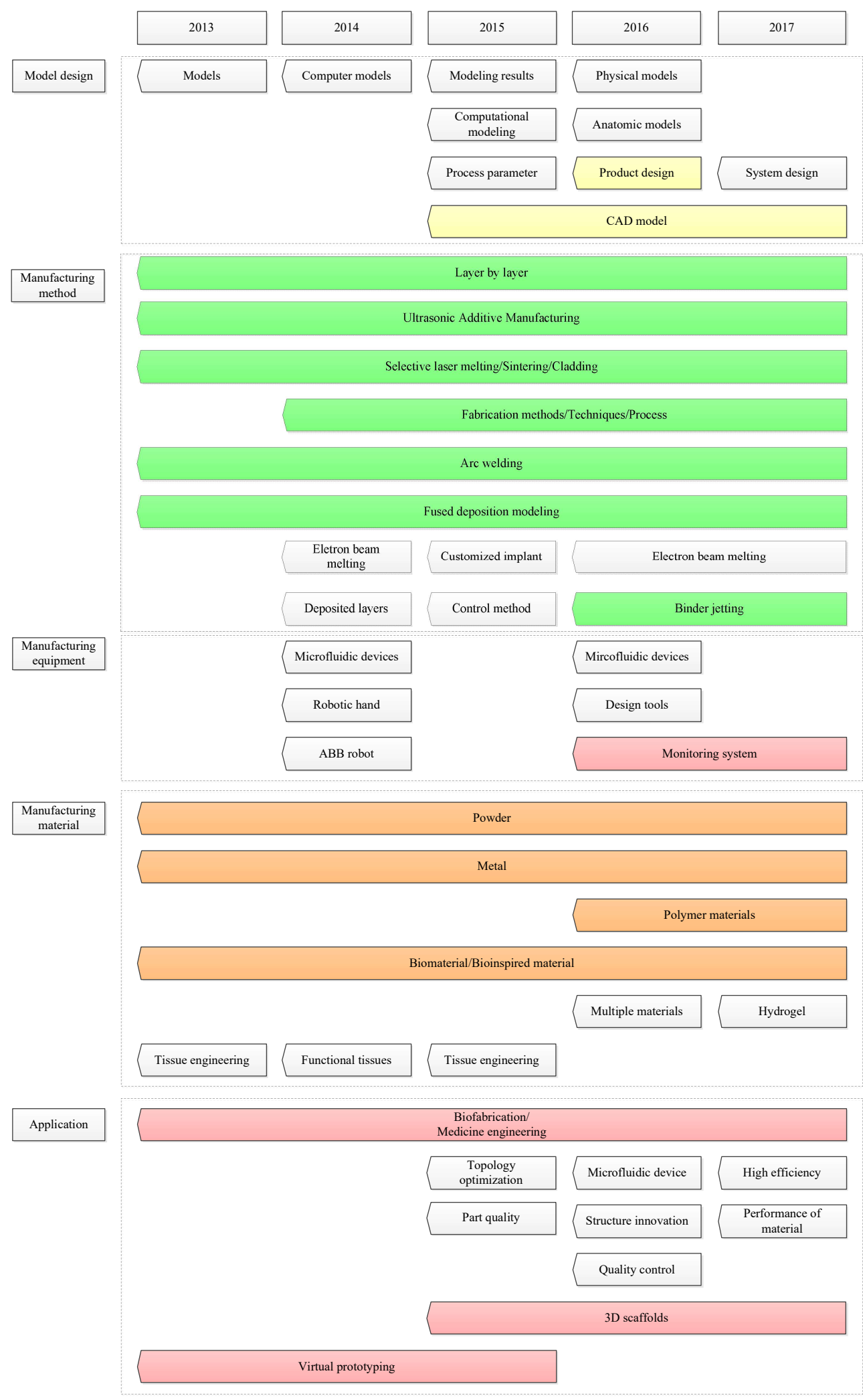

Fig. 7. The evolution pathways of the 3D printing interindustry technology linkage topic 


\section{The stability, heredity, and variability of topic evolution based on the knowledge gene}

The R\&D of 3D printing technology involves different topics at different times, and the technical terms used also have corresponding changes even for the same topic. Therefore, the five types of topic evolution relations in Fig. 6 are classified according to the Similarity calculation formula (5) and evolution pathways of topics in adjacent periods.

Specifically, most of the topics in the model design belong to both the new birth and the extinction topics; that is, these topics disappear quickly after a certain period has elapsed, but CAD modeling is the inheritance topic. In the manufacturing method, most of the topics are inherited, but electron beam melting appeared intermittent in 2014; thus, this topic belongs to the resurrection topic, while customized implant, deposited layers, and control method are temporary emergence topics. In manufacturing equipment, microfluidic devices and monitoring devices are inheritance topics, while robotic hand, $\mathrm{ABB}$ robot, and design tools are the temporary emergence topics. In manufacturing materials, powder, metal, polymer materials, and biomaterial/bioinspired material are inheritance topics; the tissue topic, since it includes tissue engineering and functional tissues, is still an inheritance topi, while multiple materials and hydrogel are the temporary emergence topics. In applications, quality biofabrication/medicine engineering, 3D scaffolds, and virtual protology are the inheritance topics, while quality and topology optimization, microfluidic device, high efficiency, structure innovation, quality control, and the performance of materials are the temporary emergence topics.

Furthermore, we apply the knowledge gene theory to knowledge evolution to obtain the following features of topic evolution:

\section{1) Stability}

The topics are widely distributed in various branches of knowledge evolution, but these topics can be classified into five aspects of 3D printing technology development, namely, model design, manufacturing methods, manufacturing equipment, manufacturing materials and application. These five aspects summarize almost all technology-related topics in 3D printing industries. The patent texts of all the topics are from R\&D institutions in different countries, so the distribution of topics has crossyear and cross-region characteristics. These five kinds of topics have a stable development trend in the span of five years, so they are consistent with the characteristics of the stability of knowledge genes.

Specifically, the most stable development in the last five years is the manufacturing method related to 3D printing technology. As shown in Table 3, according to the state and forming method of materials used in $3 \mathrm{D}$ printing, the methods of $3 \mathrm{D}$ printing technology can be divided into fused deposition modeling (FDM), stereo lithography apparatus (SLA), laminated object manufacturing (LOM), electron beam melting (EBM), selective laser melting (SLM), laser direct melting deposition (LDMD), and electron beam freeform fabrication (EBFF). These manufacturing methods have been formed in scale and have become mainstream manufacturing processes after years of development. 


\begin{tabular}{|c|c|c|c|c|}
\hline $\begin{array}{c}\text { Manufacturing } \\
\text { process }\end{array}$ & Raw material & Method & Benefits & Disadvantages \\
\hline FDM & $\begin{array}{l}\text { Filamentous } \\
\text { thermoplastic } \\
\text { material }\end{array}$ & $\begin{array}{l}\text { The forming three-dimensional } \\
\text { parts are obtained through the } \\
\text { heating extrusion of the } \\
\text { machining head and stacking } \\
\text { layer by layer under the control of } \\
\text { the computer. }\end{array}$ & $\begin{array}{l}\text { High technology } \\
\text { maturity, low cost, } \\
\text { color printing is } \\
\text { possible }\end{array}$ & $\begin{array}{l}\text { Low accuracy, } \\
\text { complex } \\
\text { components are } \\
\text { difficult to } \\
\text { manufacture }\end{array}$ \\
\hline SLA & $\begin{array}{l}\text { Photosensitiv } \\
\text { e polymer }\end{array}$ & $\begin{array}{l}\text { This photosensitive polymer uses } \\
\text { ultraviolet laser to scan liquids } \\
\text { layer by layer, thereby making it } \\
\text { possible to realize the curing of } \\
\text { liquid material. }\end{array}$ & $\begin{array}{l}\text { High precision } \\
\text { parts, high material } \\
\text { utilization }\end{array}$ & $\begin{array}{l}\text { The available } \\
\text { range is not wide, } \\
\text { high process cost }\end{array}$ \\
\hline EBM & Metal powder & $\begin{array}{l}\text { Using an electron beam as a heat } \\
\text { source in a vacuum environment, } \\
\text { the metal powder is continuously } \\
\text { spread on a bed of powder and } \\
\text { then scanned by an electron beam } \\
\text { to melt, causing the small pools to } \\
\text { fuse with each other and solidify. }\end{array}$ & $\begin{array}{l}\text { The metal parts with } \\
\text { complex structure } \\
\text { and good } \\
\text { performance can be } \\
\text { formed }\end{array}$ & $\begin{array}{l}\text { The forming size is } \\
\text { limited by the } \\
\text { powder bed and } \\
\text { vacuum chamber }\end{array}$ \\
\hline LDM & Sheeting & $\begin{array}{l}\text { The surface of the material is } \\
\text { coated with hot melt adhesive and } \\
\text { then cut and paste according to } \\
\text { the cross-section shape of each } \\
\text { layer to realize the three- } \\
\text { dimensional forming of the parts. }\end{array}$ & $\begin{array}{l}\text { It is fast and can be } \\
\text { formed into large } \\
\text { parts }\end{array}$ & $\begin{array}{l}\text { Significant } \\
\text { material waste and } \\
\text { poor surface } \\
\text { quality }\end{array}$ \\
\hline SLM & Metal powder & $\begin{array}{l}\text { The high energy laser beam is } \\
\text { used to selectively melt the metal } \\
\text { powder layer by layer. }\end{array}$ & $\begin{array}{l}\text { High precision, } \\
\text { excellent surface } \\
\text { quality, saving } \\
\text { production cost and } \\
\text { production cycle }\end{array}$ & $\begin{array}{l}\text { The size of the } \\
\text { parts is limited by } \\
\text { the laying work } \\
\text { box }\end{array}$ \\
\hline EBF & Metal wire & $\begin{array}{l}\text { First, the electron beam is used as } \\
\text { a heat source to melt the metal } \\
\text { wire, which is then stacked layer } \\
\text { by layer along a predetermined } \\
\text { path and combined with the } \\
\text { previous layer to form a } \\
\text { metallurgical bond, thus forming } \\
\text { a compact metal part. }\end{array}$ & $\begin{array}{l}\text { The molding speed } \\
\text { is fast, the } \\
\text { protection effect is } \\
\text { good, the material } \\
\text { utilization rate is } \\
\text { high, the energy } \\
\text { conversion rate is } \\
\text { high }\end{array}$ & $\begin{array}{l}\text { Poor technical } \\
\text { accuracy, and } \\
\text { subsequent surface } \\
\text { processing is } \\
\text { required }\end{array}$ \\
\hline
\end{tabular}

\section{2) Heredity}

In Fig. 6, some topics are inherited from early to late along the branch of knowledge evolution; this is consistent with the characteristics of knowledge gene heredity. The classification in Fig. 6 shows that most of the topics about the classification of manufacturing methods are inheritance topics and have good genetic characteristics. The resurrection topics will have scattered distribution, and it seems that there is no continuous genetic trajectory, but there are genetic trajectories with low or sparse knowledge connectivity; in other words, the resurrection topics still conform to the genetic characteristics.

For example, electron beam melting, a resurrection topic in the manufacturing method category, appeared in 2014, 2016 and 2017, as shown in Table 4. Keyword analysis shows that the related keywords of these topics were all involved in the literature from 2013 to 2017, with a relatively higher 
frequency of occurrence in 2016 and 2017. Therefore, this topic has good heredity, and the technical content related to the $3 \mathrm{D}$ printing industry can be well preserved in development.

TABLE 4. KEYWORDS ON MANUFACTURING METHOD IN 3D PRINTING TECHNOLOGY

\begin{tabular}{|c|c|c|c|c|c|c|c|c|c|}
\hline & 2013 & & 2014 & & 2015 & & 2016 & & 2017 \\
\hline 2 & $\begin{array}{l}\text { Electron } \\
\text { beam melting }\end{array}$ & 3 & $\begin{array}{l}\text { Electron } \\
\text { beam } \\
\text { melting }\end{array}$ & 3 & $\begin{array}{l}\text { Electron } \\
\text { beam } \\
\text { melting }\end{array}$ & $\begin{array}{l}1 \\
3\end{array}$ & $\begin{array}{l}\text { Electron } \\
\text { beam melting }\end{array}$ & $\begin{array}{l}1 \\
1\end{array}$ & Electron beam melting \\
\hline \multirow[t]{5}{*}{1} & $\begin{array}{l}\text { Electron and } \\
\text { laser beam } \\
\text { melting }\end{array}$ & 1 & $\begin{array}{l}\text { Selective } \\
\text { electron } \\
\text { beam } \\
\text { melting }\end{array}$ & 2 & $\begin{array}{l}\text { Electron } \\
\text { beam } \\
\text { additive } \\
\text { manufacturi } \\
\text { ng }\end{array}$ & 4 & $\begin{array}{l}\text { Electron } \\
\text { beam } \\
\text { additive } \\
\text { manufacturin } \\
\mathrm{g}\end{array}$ & 1 & $\begin{array}{l}\text { Electron beam } \\
\text { machining }\end{array}$ \\
\hline & & 1 & $\begin{array}{l}\text { Beam- } \\
\text { Electron } \\
\text { Melting }\end{array}$ & 1 & $\begin{array}{l}\text { Selective } \\
\text { electron } \\
\text { beam } \\
\text { melting }\end{array}$ & 3 & $\begin{array}{l}\text { Selective } \\
\text { electron } \\
\text { beam melting }\end{array}$ & 1 & $\begin{array}{l}\text { Electron beam } \\
\text { additive } \\
\text { manufacturing }\end{array}$ \\
\hline & & 1 & $\begin{array}{l}\text { Electron } \\
\text { beam } \\
\text { welding }\end{array}$ & & & & & 1 & $\begin{array}{l}\text { Laser and electron } \\
\text { beam melting }\end{array}$ \\
\hline & & & & & & & & 1 & $\begin{array}{l}\text { Beam-electron } \\
\text { melting }\end{array}$ \\
\hline & & & & & & & & 1 & Electron beam \\
\hline
\end{tabular}

\section{3) Variability}

As mentioned above, variability refers to the development of knowledge genes. Knowledge development explores and innovates on the basis of inheriting existing achievements. However, as determining variability requires investigating the relevance of the same topic and the correlation between different topics, it is necessary to further analyze the keywords under each topic.

Using the model design topic with great topic change as an example, except the topic of the CAD model (which has become an inheritance topic in recent years), all other topics are temporary emergence topics. The keywords under each temporary emergence topic are shown in Table 5:

TABLE 5. KEYWORDS ON MODEL DESIGN IN 3D PRINTING TECHNOLOGY

\begin{tabular}{|l|l|l|l|l|l|l|l|l|l|}
\hline & 2013 & & 2014 & & 2015 & & 2016 & 2017 \\
\hline 1 & RP model & 1 & Animal model & 2 & Meta model & 1 & $\begin{array}{l}\text { Animal } \\
\text { model }\end{array}$ & 3 & $\begin{array}{l}\text { Anatomic } \\
\text { model }\end{array}$ \\
\hline 1 & $\begin{array}{l}\text { Articulated } \\
\text { model }\end{array}$ & 1 & Aortic model & 1 & $\begin{array}{l}\text { Sustainability } \\
\text { models and } \\
\text { analysis }\end{array}$ & $\begin{array}{l}\text { As- } \\
\text { manufacture } \\
\text { d model }\end{array}$ & 1 & $\begin{array}{l}\text { Large-size 3D } \\
\text { model }\end{array}$ \\
\hline 1 & $\begin{array}{l}\text { Elastic } \\
\text { model }\end{array}$ & 1 & CAD model & 1 & Cancer model & 1 & $\begin{array}{l}\text { Cookie- } \\
\text { cutter model }\end{array}$ & 1 & Bead model \\
\hline 1 & $\begin{array}{l}\text { Young's } \\
\text { modulus }\end{array}$ & 1 & Cellular model & 1 & $\begin{array}{l}\text { Fracture structure } \\
\text { model }\end{array}$ & 1 & $\begin{array}{l}\text { Johnson- } \\
\text { Cook } \\
\text { Damage } \\
\text { model }\end{array}$ & 1 & $\begin{array}{l}\text { Biological } \\
\text { model }\end{array}$ \\
\hline 1 & Mold & 1 & $\begin{array}{c}\text { Material } \\
\text { model }\end{array}$ & 1 & $\begin{array}{l}\text { Thermomechanical } \\
\text { model }\end{array}$ & 1 & $\begin{array}{l}\text { External } \\
\text { ventricular } \\
\text { drain model }\end{array}$ & 1 & Bone model \\
\hline
\end{tabular}




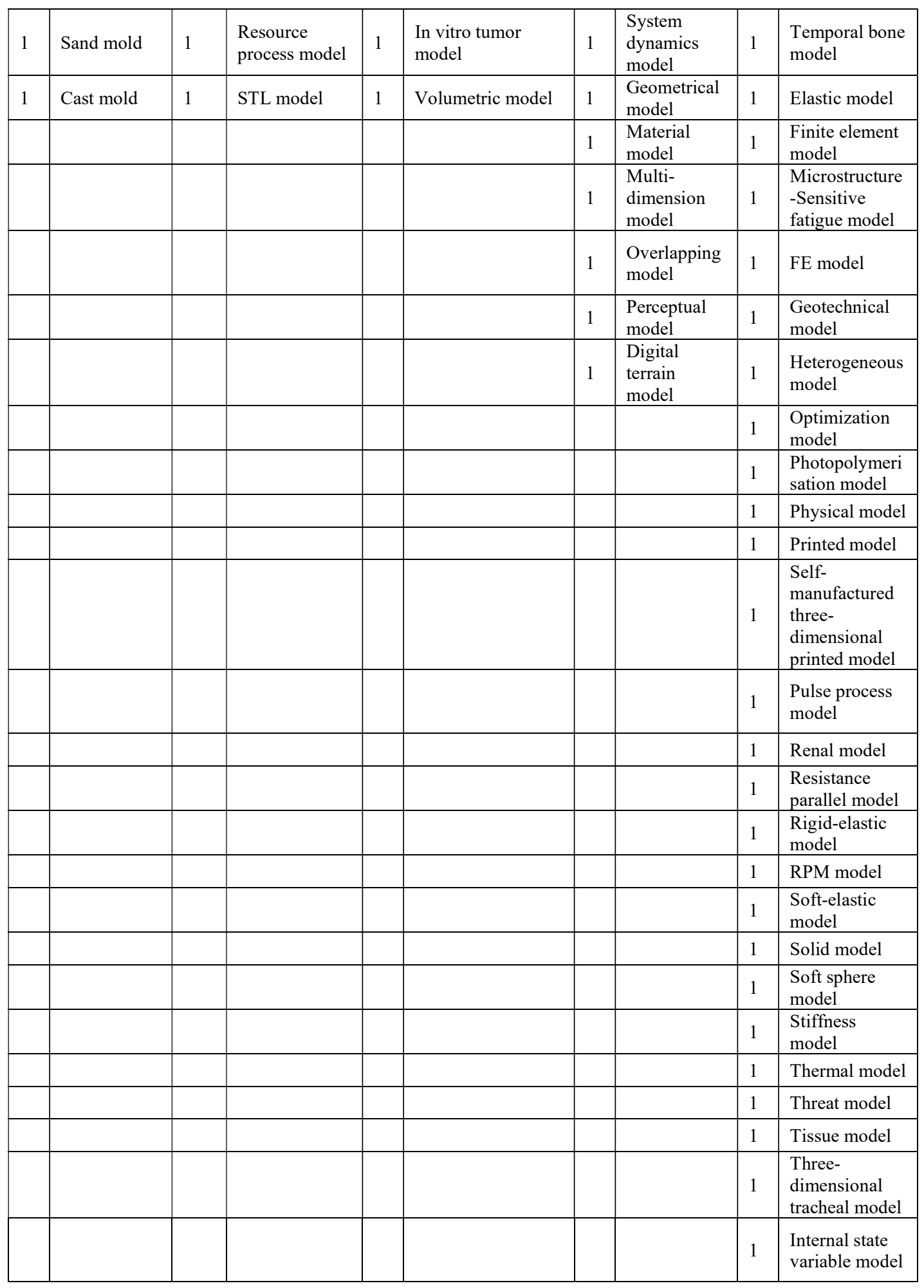

In accordance with the meaning and technical scope of each year's keyword, we find the phrases with knowledge continuity. Table 5 lists the key phrases in related terms of model design. There were fewer phrases with continuity in the topic of model design from 2013 to 2017. The topic of model design has 
great variability, and the appearance frequency of keyword documents is low; this frequency is 1 in most cases. Model making and related products develop and change rapidly, and new model keywords appear every year. Therefore, this kind of topic has strong variability.

Additionally, Table 5 also shows that new attempts and explorations are being constantly carried out in the application of models. With the rapid growth of keywords in recent years, the future development prospects of 3D printing technology-related products will be broader. Using the topics of manufacturing method with less change in topic as an example, the keywords of interindustry technology linkage under each temporary emergence topic are shown in Tables 6(A) and 6(B).

TABLE 6(A). KEYWORDS ON MANUFACTURING MATERIAL IN 3D PRINTING TECHNOLOGY

\begin{tabular}{|c|c|c|c|c|c|c|c|}
\hline & 2016 & & 2017 & & 2016 & & 2017 \\
\hline 5 & Nanotechnology & 6 & Nanocomposite & 1 & Epoxy resin & 2 & Resins \\
\hline 3 & Nanocomposite & 5 & Nanomaterials & 1 & Resin & 1 & $3 \mathrm{D}$ printer resin \\
\hline 3 & $\begin{array}{l}\text { Nanocrystalline } \\
\text { materials }\end{array}$ & 5 & Nanocomposites & 1 & $\begin{array}{l}\text { Urea-formaldehyde } \\
\text { resin }\end{array}$ & 1 & Epoxy resin \\
\hline 2 & $\begin{array}{l}\text { Nano } \\
\text { manufacturing }\end{array}$ & 3 & Nanomaterial & 1 & UV-cured resin & 1 & $\begin{array}{l}\text { PCB epoxy resin } \\
\text { substrate }\end{array}$ \\
\hline 1 & $\begin{array}{l}\text { functionalized } \\
\text { nanoparticles }\end{array}$ & 3 & Silver nanoparticles & 1 & UV-resin & 1 & $\begin{array}{l}\text { Resin for 3D- } \\
\text { printing }\end{array}$ \\
\hline 1 & $\begin{array}{l}\text { Gold } \\
\text { nanoparticles }\end{array}$ & 1 & Aligned carbon nanotubes & & & 1 & Resin for PCR \\
\hline 1 & $\begin{array}{l}\text { Multi-walled } \\
\text { carbon nanotubes }\end{array}$ & 1 & Carbon nanotubes & & & 1 & Thermoplastic resin \\
\hline 1 & Nano-texturing & 1 & Gold nanoparticles & & & 1 & $\begin{array}{l}\text { Three-dimensional } \\
\text { printer resins }\end{array}$ \\
\hline 1 & Nanoclay & 1 & Magnetic nanoparticles & & & 1 & $\begin{array}{l}\text { Ultraviolet cured } \\
\text { resin }\end{array}$ \\
\hline 1 & Nanogenerators & 1 & Nano-emissions & & & 1 & UV cured resin \\
\hline 1 & Nanoindentation & 1 & Nano-indentation & & & 1 & $\begin{array}{l}\text { UV-cured-acrylic } \\
\text { resin }\end{array}$ \\
\hline 1 & $\begin{array}{l}\text { Nanoindentation } \\
\text { test }\end{array}$ & 1 & Nano-zirconia suspension & & & 1 & $\begin{array}{l}\text { Biocompatibility } \\
\text { resin }\end{array}$ \\
\hline 1 & Nanoparticles & 1 & Nanodevices & & & 1 & Furan resins \\
\hline 1 & Nanopillars & 1 & Nanofiltration membrane & & & & \\
\hline 1 & $\begin{array}{l}\text { Nanopositioning } \\
\text { stage }\end{array}$ & 1 & Nanoinformatics & 1 & Fibre & 2 & Hollow fibers \\
\hline 1 & Nano-texturing & 1 & Nanomanufacturing & 1 & Fibre reinforcement & 2 & $\begin{array}{l}\text { Short-fiber } \\
\text { composites }\end{array}$ \\
\hline 1 & Nanoclay & 1 & Nanoparticles & 1 & Fibre/matrix bond & 2 & $\begin{array}{l}\text { Continuous carbon } \\
\text { fiber }\end{array}$ \\
\hline 1 & Nanofiber & 1 & Nanophotonics & 1 & Fibrin channels & 2 & Fibre/matrix bond \\
\hline 1 & Nanofibers & 1 & Nanopositioning & 1 & Fibroblast & 1 & Fibre printing \\
\hline 1 & Nanogenerators & 1 & Nanopositioning flexure & 1 & Fibrous dysplasia & 1 & Natural fibres \\
\hline 1 & Nanoindentation & 1 & Nanotopography & 1 & Fibre Printing & 1 & Fibres \\
\hline 1 & Nanoparticles & 1 & Nanowires & 1 & Carbon fibre & 1 & Carbon fibre \\
\hline 1 & $\begin{array}{l}\text { Functionalized } \\
\text { nanoparticles }\end{array}$ & 1 & $\mathrm{TiO} 2$ nanoparticle & & & 1 & $\begin{array}{l}\text { Short Carbon Fiber } \\
\text { Composite }\end{array}$ \\
\hline 1 & $\begin{array}{l}\text { Gold } \\
\text { nanoparticles }\end{array}$ & 1 & Micro/Nano fabrication & & & 1 & $\begin{array}{l}\text { Carbon fiber } \\
\text { reinforced plastic } \\
\text { composites }\end{array}$ \\
\hline 1 & Nanopillars & 1 & Bio-nano hybrids & & & 1 & $\begin{array}{l}\text { Fiber-reinforced } \\
\text { soft composites }\end{array}$ \\
\hline
\end{tabular}




\begin{tabular}{|l|l|l|l|l|l|l|l|}
\hline 1 & $\begin{array}{l}\text { plasmonic } \\
\text { nanorods }\end{array}$ & 1 & Silver nanofluid ink & & & 1 & $\begin{array}{l}\text { Fiber reinforced } \\
\text { thermoplastic } \\
\text { composites }\end{array}$ \\
\hline 1 & Nanostructures & 1 & Nanofiltration membrane & & & 1 & Carbon fiber \\
\hline 1 & $\begin{array}{l}\text { Core-shell } \\
\text { nanostructures }\end{array}$ & 1 & 3D micro/nanofabrication & & & 1 & Contenuous Fiber \\
\hline 1 & $\begin{array}{l}\text { Multi-walled } \\
\text { carbon nanotubes }\end{array}$ & 1 & Hybrid nanocomposite & & & 1 & glass fiber \\
\hline
\end{tabular}

TABLE 6(B). KEYWORDS ON MANUFACTURING MATERIAL IN 3D PRINTING TECHNOLOGY

\begin{tabular}{|c|c|c|c|c|c|c|c|}
\hline & 2016 & & 2017 & & 2016 & & 2017 \\
\hline \multirow[t]{10}{*}{1} & Silver Nanowire & 1 & $\begin{array}{l}\text { Polymer-based } \\
\text { nanocomposites }\end{array}$ & & & 1 & Fiberoptic \\
\hline & & 1 & $\begin{array}{l}\text { Polylactide- } \\
\text { polyglycolide } \\
\text { nanofibers }\end{array}$ & & & & \\
\hline & & 1 & $\begin{array}{l}\text { Carbon } \\
\text { nanomaterials }\end{array}$ & 2 & Hydroxyapatite & 5 & Hydroxyapatite \\
\hline & & 1 & Silver nanoparticle & & & & \\
\hline & & 1 & Gold nanoparticles & 3 & Alumina & 3 & Alumina \\
\hline & & 1 & $\begin{array}{l}\text { Magnetic } \\
\text { nanoparticles }\end{array}$ & 1 & Alumina filler & 1 & Alumina filler \\
\hline & & 1 & Carbon nanotubes & & & 1 & Porous alumina \\
\hline & & 1 & $\begin{array}{l}\text { Aligned carbon } \\
\text { nanotubes }\end{array}$ & & & 1 & Composite alumina \\
\hline & & 1 & $\begin{array}{l}\text { Nano-zirconia } \\
\text { suspension }\end{array}$ & & & & \\
\hline & & & & 2 & Hydrogel & 8 & Hydrogel \\
\hline 2 & Crystals/Crystallography & 2 & Crystallography & 2 & Hydrogels & 2 & Gelation \\
\hline 1 & Crystalline phase transition & 2 & Photonic crystals & 2 & Gelatin & 1 & $\begin{array}{l}\text { Polyion complex } \\
\text { hydrogel }\end{array}$ \\
\hline 1 & Crystallization kinetics & 1 & $\begin{array}{l}\text { Quartz crystal } \\
\text { microbalance }\end{array}$ & 1 & Colloidal gel & 1 & $\begin{array}{l}\text { Poloxamer } 407 \\
\text { hydrogel }\end{array}$ \\
\hline 1 & Phononic crystal & 1 & Crystal growth & 1 & Tough hydrogel & 1 & $\begin{array}{l}\text { Fibrin/collagen } \\
\text { hydrogel }\end{array}$ \\
\hline \multirow[t]{13}{*}{1} & X-ray Crystallography & 1 & Crystals & 1 & $\begin{array}{l}\text { PCL-gelatin } \\
\text { scaffold }\end{array}$ & 1 & Hydrogel blend \\
\hline & & 1 & Fused quartz & 1 & $\begin{array}{l}\text { Gelatin-sodium } \\
\text { alginate }\end{array}$ & 1 & Hydrogels \\
\hline & & 1 & Phononic crystals & & & 1 & $\begin{array}{l}\text { Thermo-sensitive } \\
\text { hydrogel }\end{array}$ \\
\hline & & & & & & 1 & Tough hydrogel \\
\hline & & & & & & 1 & $\begin{array}{l}\text { Capilary gel } \\
\text { electrophoresis }\end{array}$ \\
\hline & & & & & & 1 & Gel-electrophoris \\
\hline & & & & & & 1 & Gelatin \\
\hline & & & & & & 1 & $\begin{array}{l}\text { Gelatin } \\
\text { methacrylate }\end{array}$ \\
\hline & & & & & & 1 & Gelatine \\
\hline & & & & & & 1 & Microgel \\
\hline & & & & & & 1 & Sol-gel \\
\hline & & & & & & 1 & 3D gel-printing \\
\hline & & & & & & 1 & $\begin{array}{l}\text { Capilary gel } \\
\text { electrophoresis }\end{array}$ \\
\hline
\end{tabular}




\begin{tabular}{|l|l|l|l|l|l|l|l|}
\hline & & & & & 1 & $\begin{array}{l}\text { Highly transparent } \\
\text { shape memory gels }\end{array}$ \\
\hline & & & & & & 1 & $\begin{array}{l}\text { Gelatin } \\
\text { methacrylate }\end{array}$ \\
\hline & & & & & & 1 & Aerogels graphene \\
\hline & & & & & 1 & $\begin{array}{l}\text { Aerosols } \\
\text { monodisperse radio- } \\
\text { labeled }\end{array}$ \\
\hline
\end{tabular}

According to the actual meaning of the keywords and the similarity between the keywords, Tables 6(A) and 6(B) list words that appeared only briefly in 2016 and similar words that appeared in 2017. From 2016 to 2017, there were many transient words in manufacturing method topics, and the frequency of each word was low, mostly 1 . We can infer that the manufacturing method topics are highly innovative, the processing methods of various materials are changing rapidly, old keywords are eliminated and new keywords appear every year between 2016 and 2017. Thus, the variability of manufacturing method topics is strong, all R\&D entities are constantly innovating, and the whole industry is eliminating inefficient and inappropriate technologies and developing energy-saving and efficient technologies. From 2016 to 2017, the keywords in manufacturing method topics increased significantly, thus showing that the rapid development of manufacturing technology will promote the continuous and rapid development of technology linkages between 3D printing industries.

In summary, according to the five topics of interindustry technology linkage patents in 3D printing, manufacturing methods have developed to a mature stage, while model design, manufacturing equipment, manufacturing materials and research applications are still in the growth stage. From 2013 to 2017 , 3D printing technology surpassed manufacturing process innovation and entered the stage of material innovation. In particular, the technology of manufacturing materials changes most rapidly, with the most hidden technological opportunities and innovation space. In addition, as the final foothold downstream of the industrial chain, the topic of research application has a large demand after years of development.

\section{DisCUSSIONS AND CONCLUSIONS}

Based on knowledge evolution theory and by using 3D printing technology as an empirical object, the Lingo algorithm is used to extract and cluster the topics of interindustry technology linkages in 3D printing. Then, the knowledge gene in knowledge evolution is applied to analyze the topics' evolutionary characteristics, including stability, heredity and variability, to offers a better understanding of the development trend and opportunity of 3D printing technology. We obtain the following theoretical contributions and practical implications:

First, this study constructs an evolution analysis framework of interindustry technology linkage topics, which is composed of the Lingo algorithm and knowledge gene theory. Compared with the existing topic evolution analysis methods [49-53], the proposed analysis framework has the following 
advantages: in the aspect of analyzing topic dynamic change characteristics, this study embeds the similarity formula into the Lingo algorithm to calculate the similarity degree between adjacent time topics, which can effectively show the degree of inheritance or variation of topics over time. However, the existing methods [49-53] only extracted the topics in different time periods, and then counted the changes of the number of topics on different time nodes. In essence, they only conducted a simple statistical analysis of several static time points of technical topics, and then reflect the changes of topics by investigating their differences at multiple static time points, without in-depth analysis of the inheritance or variation degree of topics in different periods, that lead to a very limited understanding of the evolution characteristics of topics.

In term of topic evolution relationship and pathway, this paper uses the knowledge gene theory to construct the association relationship between the current time topic and its forward topic and backward topic, and this relationship can be divided into five categories: new birth, extinction, temporary appearance, inheritance and resurrection. Then according to these five kinds of relationships, three kinds of evolution characteristics of the topic, namely stability, heredity and variability, are reasonably concluded. By contrast, the former methods [49-53] only show the evolution pathway according to the changes of topics in quantity or meaning at different time points, so the results are more superficial and rough. What's worse, the results of topic evolution by them can only show the temporal distribution of the number or meaning of topics, and it is difficult to show the reasons behind the changes and the state. In general, our method can overcome the shortcomings of existing methods which are difficult to describe the topic evolution relationship, effectively expose the internal evolution characteristics of the topic and explain its underlying reasons.

Further, the interindustry technology linkage is represented by citation relationship data among crossindustry patents and their families, and the Lingo algorithm is used to mine unstructured patent text topics with citation relationship in our study. This breaks the shortcomings of previous research in interindustry technology linkage topic analysis and data sources. Specifically, existing studies [12-18] only measure the impact of interindustry technology linkage based on empirical analysis; although some studies [6, 20-24] applied the co-occurrence matrix to examine the features of interindustry technology linkage, it is difficult to represent the technical relevance of different patents because the co-occurrence matrix represents the same topic term in different patents, that is, different patents show the same topic technology.

Based on the perspective of citation relationship between patents, this study selects the cross-industry patent literature with citation relationship to investigate the interindustry technology linkage completely from the technical level. Therefore, the cross-industry-based patent citation information can accurately represent the characteristics of interindustry technology linkage. Moreover, the previous research [2024] is mainly based on the co-occurrence perspective of patent classification number. Patent classification number is to classify and retrieve patent literature from a macro perspective. Hence, the mining of technical topic based on the macro patent classification number is difficult to fully show the 
core technical topics in patent literature. In contrast, this study uses the Lingo model to extract the topic from the perspective of unstructured text describing the content of the technical topic. The patent topic derived on this basis fully represents the critical technical content described in the patent text. Consequently, the patent topic analysis based on patent literature, which is unstructured data, breaks through the traditional research only based on structured data such as IPC and Derwent manual code, and the results obtained by unstructured patent text can demonstrate the core topic characteristics of patent technology in a more in-depth and comprehensive way.

Besides, this study analyzes the evolution characteristics of 3D printing technology through cross industry patent citation data. Previous studies [62-67] completely ignored this cross industry feature and only given the overall development trend of 3D printing technology from the perspective of macro patent quantity statistics, which could not reflect the application and integration trend of 3D printing technology in different industries. Our results can afford a better understanding of topic evolution of interindustry technology linkage in 3D printing, and provide a preliminary judgment for its future development trend. Concretely, we get the following three evolution characteristics of interindustry technology linkage topic in 3D printing: (1) There were five topics of interindustry technology linkage in 3D printing in 2013-2017, namely, model design, manufacturing methods, manufacturing equipment, manufacturing material and application.

Overall, the five topics have certain heredity; that is, the previous technologies have left some imprints on existing technologies, thus indicating that most 3D printing technologies maintained stable innovation vitality and development trends. (2) The topic of manufacturing methods has the strongest stability, thus indicating that manufacturing has been relatively mature after years of development, and large R\&D investment and long-term exploration are required to obtain a breakthrough development in the future. (3) The topics of manufacturing material related to 3D printing technology have the strongest variability. Specifically, the materials used in various interindustry technologies are constantly advancing and improving. Therefore, the most promising field for the future development of $3 \mathrm{D}$ printing technology is manufacturing materials, which have the greatest potential for future breakthroughs and more technological opportunities. These results show that the proposed method and data source in this paper are effective. Therefore, our method can provide a powerful tool and idea for analyzing the evolution of other interindustry technology linkage topics. At the same time, the evolutionary characteristics analysis method based on the knowledge gene also provides the researchers and enterprise decision makers with the decision support of technology R\&D and investment.

In future works, we can also carry out extensive research from the following three aspects: (1) by dynamically tracking technology product trading data, network data, research data and expert interview data, this kind of multisource heterogeneous data is integrated to analyze the evolution of topics relating to technology to mine more characteristics of topic evolution; (2) the research integrates economic, political, and even weather and other environmental perspectives to explore the influence of technology association between industries and identify the multilevel influencing factors of the evolution of 
technology linkage topics between industries; and (3) the network security issues of 3D printing technology have received increasing attention. Blockchain is an important tool to address the security issues of 3D printing technology. Therefore, future research can specifically analyze the topic evolution trend regarding the correlation between printing technology and blockchain technology to precisely find the direction and pathway of addressing 3D printing technology security issues.

\section{REFERENCES}

[1]. H. Jiang, and X. Lu, "Study on industry classification and selection model based on the view of industrial technology innovation," China Ind. Econ., vol. 9, pp. 47-56, 2019.

[2]. K. Pavitt, M. Robson, and J. Townsend, "Technological accumulation, diversification and organization in UK companies 1945 1983,” Manage. Sci., no. 35, pp. 81-99, 1989.

[3]. C. Luan, Z. Liu, and X. Wang, "Divergence and convergence: technology-relatedness evolution in solar energy industry," Scientometrics, vol. 97, no. 2, pp. 461-475, 2013.

[4]. V. Allee, "The knowledge evolution". Butterworth-Heinemann Press, Oxford, United Kingdom, 1997

[5]. J. He, W. Lv, "Origin, research and development of knowledge memetics," Stud. Sci. Sci., vol. 29, no. 10, pp. 1454-1459, 2011.

[6]. S. Rodan, and C. Galunic, "More than network structure: How knowledge heterogeneity influences managerial performance and innovativeness," Strateg. Manag. J., vol. 25, no. 6, pp. 541-562, 2004.

[7]. F. Barthelmé, J. Ermine, and C. Rosenthal-Sabroux, "An architecture for knowledge evolution in organizations," Eur. J. Oper. Res., vol. 109, no. 2, pp. 414-427, 1998.

[8]. C. W. Arnold, A. Oh, S. Chen, and W. Speier, "Evaluating topic model interpretability from a primary care physician perspective," Comput. Meth. Prog. Bio., Vol. 124, pp. 67-75, 2016.

[9]. R. Noorani. "3D printing: technology, applications, and selection," CRC Press, pp. 2-7,2017.

[10]. L. Huang, Y. Shi, F. Wu. "Study on the correlation characteristics of new industries based on technical perspective: The case of 3D printing-related industries." In 2015 Portland International Conference on Management of Engineering and Technology (PICMET), pp. 680-688. IEEE, 2015.

[11]. M. Frankel, "Obsolescence and technological change in a maturing economy," Am. Econ. Rev., vol. 45, pp. 296-319. 1955.

[12]. D. J. Teece, "Firm organization, industrial structure, and technological innovation," J. Econ. Behav. Organ., vol. 31, pp. 193-224, 1996.

[13]. D. Foray, and C. Freeman, "Technology and the wealth of nations: the dynamics of constructed advantage," London and New York. Pinter Publishers, pp. 194-207, 1993.

[14]. K. I. Carlaw, and R. G. Lipsey, "Externalities versus technological complementarities: a model of GPTdriven, sustained growth," Conference in Honour of the $20^{\text {th }}$ Anniversary of Nelson and Winter's Book "An Evolutionary Theory of Economic Change, pp. 12-15, 2001, Available: http://www.sfu.ca/rlipsey

[15]. J. Cantwell, and G. D. Santangelo, "M\&As and the global strategies of TNCs," Dev. Econ., vol. 40, no. 4, pp. 400-434, 2002.

[16]. M. S. Kim, and Y. Park, "The changing pattern of industrial technology linkage structure of Korea: Did the ICT industry play a role in the 1980s and 1990s?" Technol. Forecast. Soc. Change, vol. 76, no. 5, pp. 688699, 2009.

[17]. F. H. Liang, "Does foreign direct investment improve the productivity of domestic firms? Technology spillovers, industry linkages, and firm capabilities," Res. Policy, vol.46, no.1, pp. 138-159, 2017.

[18]. Y. Zhou, W. Liu, X. Lv, X. Chen, and M. Shen, "Investigating interior driving factors and cross-industrial linkages of carbon emission efficiency in China's construction industry: Based on Super-SBM DEA and GVAR model," J. Clean. Prod., vol. 241, 118322, 2019.

[19]. Q. Ke, "An analysis of the evolution of science-technology linkage in biomedicine," J. Informetr., vol. 14, no. 4, 101074, 2020.

[20]. S. Neelam and S. K. Sood, "A Scientometric Review of Global Research on Smart Disaster Management," in IEEE T. Eng. Manage., vol. 68, no. 1, pp. 317-329, 2021.

[21]. J. Law, and J. Whittaker, "Mapping acidification research: a test of the co-word method," Scientometrics, vol. 23, no. 3, pp. 417-461, 1992.

[22]. S. Petralia, "Mapping general purpose technologies with patent data," Res. Policy, vol. 49, no. 7, 104013, 2020.

[23]. C. Kim, and H. Lee, "A patent-based approach for the identification of technology-based service 
opportunities," Comput. Ind. Eng., vol.144, 106464, 2020.

[24]. C. Lee, D. Jeon, J. M. Ahn, and O. Kwon, "Navigating a product landscape for technology opportunity analysis: A word2vec approach using an integrated patent-product database," Technovation, pp. 96-97, 102140, 2020.

[25]. T. H. Morgan, "The theory of the gene,” New Haven: Yale University Press, 1926.

[26]. R. Dawkins, "The selfish gene," London: Oxford University Press, 1976.

[27]. T. Zhang, J. Zhao, and X. Xi, "Research on level transition model of organizational knowledge creation. $J$. Ind. Eng. Eng. Manage., vol. 27, no. 4, pp. 41-52, 2013.

[28]. X. Sun, and K. Ding, "Research on the relationship between science and technology based on knowledge gene discovery. Inform. Stud. Theory A, vol. 40, no. 6, pp. 23-26, 2017.

[29]. E. Garfield, "Citation Indexing: Its Theory and Application in Science Technology and Humanities," New York, 1979.

[30]. C. Y. Wong, and L. Wang, "Trajectories of science and technology and their co-evolution in BRICS: insights from publication and patent analysis," J. Inf. Secur., no. 9, pp.90-101, 2015.

[31]. A. Breitzman, and P. Thomas, "The emerging clusters model: a tool for identifying emerging technologies across multiple patent systems," Res. Policy, vol. 44, pp,195-205, 2015.

[32]. Z. Huang, H. Chen, A. Yip, et al., "Longitudinal patent analysis for nanoscale science and engineering: country, institution and technology field," J. Nanopart. Res., vol. 5 no. 3, pp.333-363, 2003.

[33]. C. Chen, and D. Hicks, “Tracing knowledge diffusion," Scientometrics, vol. 59, no. 2, pp.199-211, 2004.

[34]. T. Daim, K. K. Lai, H. Yalcin, and F. Alsoubie, V. Kumar, "Forecasting technological positioning through technology knowledge redundancy: Patent citation analysis of IoT, cybersecurity, and Blockchain," Technol. Forecast. Soc. Change, vol. 161, no. 120329, 2020.

[35]. X. Li, M. Fan, Y. Zhou, J. Fu, F. Yuan, and L. Huang, "Monitoring and forecasting the development trends of nanogenerator technology using citation analysis and text mining," Nano Energy, vol. 71, 104636, 2020.

[36]. M. Y. Tsay, and Z.W. Liu, "Analysis of the patent cooperation network in global artificial intelligence technologies based on the assignees," World Pat. Inf., vol. 63, 10200, 2020.

[37]. C. Yin, H. Gu, and S. Zhang, "Measuring technological collaborations on carbon capture and storage based on patents: A social network analysis approach," J. Clean. Prod., vol. 274, 122867, 2020.

[38]. S. Jung, W. C. Yoon. "An alternative topic model based on Common Interest Authors for topic evolution analysis." Journal of Informetrics, vol. 14, no. 3: 101040, 2020.

[39]. G. Dosi, "Technological paradigms and technological trajectories: a suggested interpretation of the determinants and directions of technical change," Res. Policy, vol. 11, pp. 147-162, 1982.

[40]. J. Chen, and S. Huang, "Study on evolution of enterprise technology innovation system," J. Ind. Eng. Eng. Manage., vol. 28, no. 4, pp. 218-227, 2014.

[41]. X. Wang, and A. McCallum, "Topics over time: a non-Markov continuous-time model of topical trends," Proceedings of the 12th ACM SIGKDD International Conference on Knowledge Discovery and Data Mining, ACM, pp, 424-433, 2006.

[42]. D. M. Blei, and J. D. Lafferty, "Dynamic topic models," Proceedings of the Twenty-Third International Conference on Machine Learning (ICML 2006), Pittsburgh, Pennsylvania, USA, 2006, pp. 113-120.

[43]. R. Gerlach, C. Carter, and R. Kohn, "Efficient Bayesian inference for dynamic mixture models," J. Am. Stat.Assoc., vol. 95, pp. 819-828, 2000.

[44]. L. ALSumait, D. Barbara, and C. Domeniconi, "On-line LDA: adaptive topic models for mining text streams with applications to topic detection and Tracking," in Proc. 8th IEEE Int. Conf. Data Mining, Pisa, 2008, pp. 3-12.

[45]. C. Wang, J. W. Paisley, and D. M. Blei, "Online variational inference for the hierarchical Dirichlet process," Proceedings of the 14th International Conference on Artificial Intelligence and Statistics, pp, 752-760, 2011.

[46]. A. Ahmed, and E. Xing, "Dynamic non-parametric mixture models and the recurrent Chinese restaurant process: with applications to evolutionary clustering," in Proc. SIAM Int. Conf. Data Mining. Atlanta, USA: SIAM, 2008, pp. 219-230.

[47]. A. Ahmed, and E. P. Xing, "Timeline: a dynamic hierarchical Dirichlet process model for recovering birth/death and evolution of topics in text stream," in Proc. 26th Conf. Uncertainty in Artificial Intelligence, Arlington Virginia, USA: AUAI Press, 2010, pp. 20-29.

[48]. W. S. Elshamy, "Continuous-time infinite dynamic topic models," Manhattan, Kansas: Kansas State University, 2013.

[49]. R. C. Basole, H. Park and R. O. Chao, "Visual Analysis of Venture Similarity in Entrepreneurial Ecosystems," in IEEE T. Eng. Manage., vol. 66, no. 4, pp. 568-582, Nov. 2019,

[50]. J. Wang, J. Lv, "Tag-informed collaborative topic modeling for cross domain recommendations," KnowlBased Syst., vol. 203, 106119, 2020.

[51]. S. Xu, L. Hao, G. Yang, K. Lu, and X. An, “A topic models based framework for detecting and forecasting emerging technologies,” Technol. Forecast. Soc. Change, vol. 162, 120366, 2021. 
[52]. L. Shi, G. Song, G. Cheng, and X. Liu, “A user-based aggregation topic model for understanding user's preference and intention in social network," Neurocomputing, vol. 413, pp. 1-13, 2020.

[53]. C. Wei, L. Chaoran, L. Chuanyun, K. Lingkai and Y. Zaoli, "Tracing the Evolution of 3-D Printing Technology in China Using LDA-Based Patent Abstract Mining," 2020, in IEEE T. Eng. Manage., doi: 10.1109/TEM.2020.2975988.

[54]. C. Wu, and H. Leu, "Examining the trends of technological development in hydrogen energy using patent co-word map analysis," Int. J. Hydrogen Energ., vol. 39, no. 33, pp. 19262-19269, 2014.

[55]. J. Yun, and Y. Geum, "Automated classification of patents: A topic modeling approach," Comput. Ind. Eng., vol. 147, 106636, 2020.

[56]. U. H. Govindarajan, A. J. C. Trappey, and C. V. Trappey, "Intelligent collaborative patent mining using excessive topic generation," Adv. Eng. Inform., vol. 42, no. 100955, 2019.

[57]. X. Zheng, M. A. Aborisade, S. Liu, et al., "The history and prediction of composting technology: A patent mining," J. Clean. Prod., vol. 276, 124232, 2020.

[58]. F. T. Rogers, "Patent text similarity and cross-cultural venture-backed innovation," J. Behav. Exp. Financ., vol. 26, 100319, 2020.

[59]. N. Shahrubudin, T. C. Lee, and R. Ramlan, "An overview on 3D printing technology: Technological, materials, and applications," Procedia Manufacturing, vol. 35, pp.1286-1296, 2019.

[60]. H. K. Chan, J. Griffin, J. J. Lim, F. Zeng, and A. S. Chiu, "The impact of 3D Printing Technology on the supply chain: Manufacturing and legal perspectives," Int. J. Prod. Econ., vol. 205, pp.156-162, 2018.

[61]. M. R. Khosravani, and T. Reinicke, "On the environmental impacts of 3D printing technology," Appl. Mater. Today, vol. 20, p.100689, 2020.

[62]. S. Park, J. Kim, H. Lee, D. Jang, and S. Jun, "Methodology of technological evolution for three-dimensional printing," Ind. Manage. Data Syst., vol. 116, no. 1, pp. 122-146.

[63]. A. J. Trappey, C. V. Trappey, and K. L. Lee, "Tracing the evolution of biomedical 3D printing technology using ontology-based patent concept analysis," Technol. Anal. Strategic Manag., vol. 29, no.4, pp.339-352, 2017.

[64]. Y. Huang, D. Zhu, Y. Qian, Y. Zhang, A. L. Porter, Y. Liu, and Y. Guo, "A hybrid method to trace technology evolution pathways: a case study of 3D printing," Scientometrics, vol. 111, no. 1, pp.185-204, 2017.

[65]. Y. Zhou, H. Lin, Y. Liu, and W. Ding, "A novel method to identify emerging technologies using a semisupervised topic clustering model: a case of 3D printing industry," Scientometrics, vol. 120, no. 1, pp.167$185,2019$.

[66]. Z. Wang, A. L. Porter, X. Wang, and S. Carley, “An approach to identify emergent topics of technological convergence: A case study for 3D printing,” Technol. Forecast. Soc. Change, vol. 146, pp.723-732, 2019.

[67]. Z. Miao, J. Du, F. Dong, Y. Liu, and X. Wang, "Identifying technology evolution pathways using topic variation detection based on patent data: A case study of 3D printing," Futures, vol. 118, p.102530, 2020.

[68]. L. Wang, S. Jiang, and S. Zhang, "Mapping technological trajectories and exploring knowledge sources: A case study of 3D printing technologies," Technol. Forecast. Soc. Change, vol. 161, p.120251, 2020.

[69]. O. Stanislaw, and W. Dawid, "A concept-driven algorithm for clustering search results," IEEE Comput. Soc., vol. 20, no. 3, pp. 48-54, 2005.

[70]. C. R. Darwin, “On the origin of species: by mean of natural selection," Leipzig: Verlag Philipp Reclam,1859.

[71]. J. B. Lamarck, "Philosophie zoologique,” Paris: Nou-velle Edition, 1809.

[72]. B. Mckelvey, "Organizational systematics: taxonomic lessons from biology," Manage. Sci., vol. 24, no. 13, pp. 1428-1440. 1978.

[73]. K. Eriksson, J. Johanson, A. Majkgård, et al., "Effect of variation on knowledge accumulation in the internationalization process," Int. Stud. Manage. Organ., vol. 30, no. 1, pp. 26-44, 2016.

[74]. D. C. Manning, P. Raghavan, and H. Schütze, "Introduction to information retrieval," Cambridge University Press, 2008. 


\section{Author's biography:}

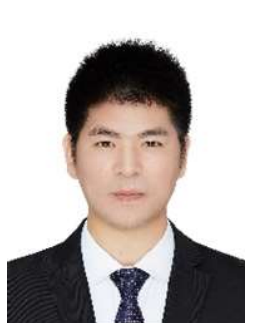

Zaoli Yang received his B.Sc. degree from the Harbin University of Commerce, and a M.Sc. and Ph.D. degrees from Harbin Engineering University, China. He is an Associate Professor in management science and engineering at the College of Economics and Management, Beijing University of Technology. His main research interests include multi-decision making, fuzzy set theory, and data mining. His research has been published in academic journals, including IEEE Transactions on Engineering Management, Expert Systems with Applications, Computers and Industrial Engineering, Technological Forecasting \& Social Change, Journal of Cleaner Production, IEEE ACCESS.

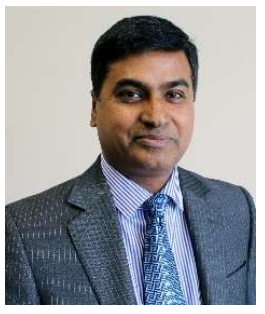

Nazrul Islam received his $\mathrm{PhD}$ in innovation management from Tokyo Institute of Technology. He is currenly an Associate Professor of Innovation/Entrepreneurship and an Interdisciplinary Pathway Lead for global political economy at the University of Exeter Business School, England, UK. His research interests include innovation in high-tech industries, the management of emerging and discontinuous innovations. His research was published in the leading international journals and he has complemented his peer reviewed journal efforts with three books. Prof Islam's research received awards including the 'Brad Hosler Award for Outstanding Paper' from USA; and the 'Pratt \& Whitney Canada Best Paper Award' from Canada. Prof Islam serves on the board of directors for Business and Applied Sciences Academy of North America. He currently serves an Associate Editor of Technological Forecasting \& Social Change and Editor-in-Chief of International Journal of Technology Intelligence and Planning.

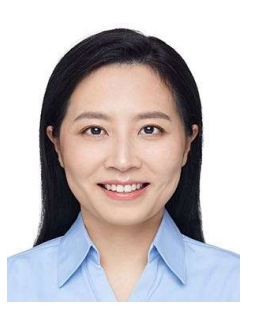

Yuanyuan Shi received the M.Sc. and Ph.D. degrees from the Beijing University of Technology, Beijing, in 2014 and 2018, respectively. She is Senior Engineer with the Ministry of Transport Planning and Research Institute. Her research interests include data mining, intelligent transportation and industrial technology forecast. He has published many journal (Including Chinese academic journals) and conference papers in his research field.

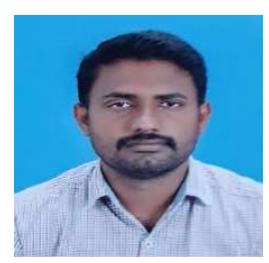

K.Venkatachalam received his Bachelors in Information Technology in 2005, Master's in Computer Science and Engineering in 2008 and $\mathrm{PhD}$ in Computer Science and Engineering in 2018. He is currently working as an Assistant Professor in the Department of Computer Science and Engineering, CHRIST (Deemed to be University), Bangalore, India. He had published several articles in peer-reviewed journals and his research interest includes Data Mining, Web services, semantic web services, Distributed computing, Cloud Computing.

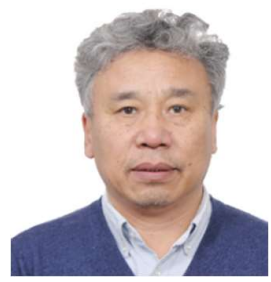

Lucheng Huang is a Professor and a Ph.D. Tutor of management science and engineering with the College of Economics and Management, Beijing University of Technology, since 1998. He is currently a Distinguished Professor in Beijing city. His main research interests include innovation management, tech mining, and data mining. He has published over 200 journals and conference papers in his research field, and many of them are in top-tier highimpact journals. 